\title{
Design Method for Flux-Concentrating Permanent-Magnet Traction Machine Based on Voltage-Parameter Map
}

\author{
Ki-Doek Lee ${ }^{(D}$, Jeong-Jong Lee, Myung-Hwan Yoon and Joon-Sung Park * $\mathbb{D}$ \\ Intelligent Mechatronics Research Center, Korea Electronics Technology Institute, Gyeonggi-do, \\ Seongnam-si 13509, Korea; kdlee@keti.re.kr (K.-D.L.); leejj@keti.re.kr (J.-J.L.); yoonmh@keti.re.kr (M.-H.Y.) \\ * Correspondence: parkjs@keti.re.kr
}

check for updates

Citation: Lee, K.-D.; Lee, J.-J.; Yoon, M.-H.; Park, J.-S. Design Method for Flux-Concentrating

Permanent-Magnet Traction Machine Based on Voltage-Parameter Map. Energies 2021, 14, 5311. https:// doi.org/10.3390/en14175311

Academic Editor: Adolfo Dannier

Received: 28 June 2021

Accepted: 5 August 2021

Published: 26 August 2021

Publisher's Note: MDPI stays neutral with regard to jurisdictional claims in published maps and institutional affiliations.

Copyright: (c) 2021 by the authors. Licensee MDPI, Basel, Switzerland. This article is an open access article distributed under the terms and conditions of the Creative Commons Attribution (CC BY) license (https:/ / creativecommons.org/licenses/by/ $4.0 /)$.

\begin{abstract}
A voltage-parameter map (VP-Map) is proposed for predicting the performance of electric vehicles (EVs) and hybrid EVs (HEVs), which varies with respect to the parameters in a variable load and flux-weakening range, and determining the design parameters. Through this, the maximum torque that can be generated at the maximum speed, the input current for generation of the rated torque, and whether the vehicle is operable with a light load are predicted, and the design parameters suitable for the 120-kW class interior permanent-magnet (PM) synchronous motor for HEVs, which is the target electric motor of this study, are determined. A flux-concentrating PM synchronous motor (FCPMSM) is proposed that can be designed using the desired design parameters depending on the degree of the flux concentration. The validity of the VP-Map was verified by analyzing the characteristics of three types of FCPMSMs with different parameter combinations, and a PM synchronous motor for an EV having a high output, high efficiency, and high-power factor was designed. Lastly, the requirements were checked, and the analysis was validated by testing the designed motor.
\end{abstract}

Keywords: interior permanent-magnet synchronous motor (IPMSM); traction motor; electric vehicle (EV); hybrid electric vehicle (HEV); voltage-parameter map (VP-Map); power density; power factor

\section{Introduction}

The latest technology trend of traction motors includes the use of higher voltages and higher motor speeds to improve the power density. An increase in the battery voltage decreases the current in the motor coil and the inverter; thus, the loss of the entire electric drive system can be reduced. While an increase in the motor speed allows the motor to be smaller and lighter and have a higher output power density, the high-speed efficiency characteristic is deteriorated, owing to the increase in the core loss. To resolve this problem, electrical steel plates with a low core loss for EVs are being developed, and the shape of the rotor is being improved to ensure mechanical safety at high speeds. Higher outputs of traction motors could have been realized with such an improvement in design technology, as a result of which both the fuel efficiency and output characteristics could be improved. Similarly, a traction motor for HEVs/EVs is required not only to be small, light, and highly efficient but also to have high torque and extensive rated output characteristics at a low speed, durability and reliability, lower noise, and a low price. The objective of this study was to make the entire electric drive system smaller and lighter and improve the efficiency. For this, not only must the traction motor be smaller and lighter and have higher efficiency, but the design must also achieve a higher power factor. If the power factor of the traction motor is improved, as the apparent power, which is the output of the inverter generating the same torque, is reduced, the inverter can be smaller and lighter and have higher efficiency [1,2].

Most of the previous studies on permanent-magnet (PM) synchronous motors involved calculations of the motor parameters and analysis of characteristics via magnetic 
circuit analysis and loss reduction via finite-element analysis [3-6], improvement of the torque density [7-10], reduction of the torque ripple and cogging torque [11-13], optimum design [14,15], etc. Almost no studies have investigated the design sequence for a motor that satisfies the desired characteristics. Although E. S. Hamdi [16] and others have partially covered the design sequence, in most cases, the design was performed using many empirical values. Until now, there have been almost no studies on a method for designing a PM synchronous motor with a high-power factor and a method for determining design parameters suitable for HEVs/EVs. Regarding studies on the power factor of PM synchronous motors, Y. Wang, D. Ionel, X. Wang, F. Zhao, and other researchers analyzed the power-factor characteristics of motors with different stator and rotor shapes [17-20], and Y. Kataoka analyzed the power-factor characteristics for different combinations of the pole number and slot number [21]. However, only the power factor characteristics were analyzed; there have been almost no studies on a method for improving the power factor at the desired design point. Although the output equation may be used for determining the design parameters of a PM synchronous motor, there are difficulties in determining the design parameters suitable for HEVs/EVs under a variable load, as only the characteristics of the maximum load can be grasped; the output characteristics under the desired load are difficult to grasp. The objective of this study was to develop a method for determining the design parameters for HEVs/EVs under a variable load and to thereby design a traction motor not only smaller and lighter but also having a high-power factor.

\section{Characteristic Analysis of Interior pm Synchronous Motor (IPMSM) According to Design Parameters}

In this paragraph, the output characteristics of the motor were analyzed using the torque equation and the voltage equation for different values of $\lambda_{\mathrm{pm}}, \mathrm{L}_{\mathrm{d}}$, and $\mathrm{L}_{\mathrm{q}}$, where $\lambda_{\mathrm{pm}}$ is no-load flux linkage, and $\mathrm{L}_{\mathrm{d}}, \mathrm{L}_{\mathrm{q}}$ are $\mathrm{d}$-axis, $\mathrm{q}$-axis inductance. The number of poles, torque, speed, phase voltage restriction, and phase current restriction required for the parameter analysis are shown in Table 1.

$$
\begin{gathered}
\mathrm{T}=\frac{3}{2} \mathrm{p} \lambda_{\mathrm{pm}} \mathrm{I}_{\mathrm{a}} \cos \beta+\frac{3}{4} \mathrm{p}\left(\mathrm{L}_{\mathrm{q}}-\mathrm{L}_{\mathrm{d}}\right) \mathrm{I}_{\mathrm{a}}{ }^{2} \sin 2 \beta \\
\mathrm{V}_{\mathrm{a}}=\sqrt{\left(\mathrm{R}_{\mathrm{s}} \mathrm{i}_{\mathrm{d}}-\omega_{\mathrm{em}} \mathrm{L}_{\mathrm{q}} \mathrm{i}_{\mathrm{q}}\right)^{2}+\left(\mathrm{R}_{\mathrm{s}} \mathrm{i}_{\mathrm{q}}+\omega_{\mathrm{em}} \mathrm{L}_{\mathrm{d}} \mathrm{i}_{\mathrm{d}}+\omega_{\mathrm{em}} \lambda_{\mathrm{pm}}\right)^{2}} \\
\mathrm{~V}_{\mathrm{o}}=\sqrt{\left(\omega_{\mathrm{em}} \mathrm{L}_{\mathrm{q}} \mathrm{i}_{\mathrm{q}}\right)^{2}+\left(\omega_{\mathrm{em}} \mathrm{L}_{\mathrm{d}} \mathrm{i}_{\mathrm{d}}+\omega_{\mathrm{em}} \lambda_{\mathrm{pm}}\right)^{2}}
\end{gathered}
$$

Table 1. Initial values for analysis of output characteristics.

\begin{tabular}{ccc}
\hline Specification & Value & Unit \\
\hline Poles & 10 & - \\
Torque at rated speed & 420 at 2843 & Nm at rpm \\
Torque at max speed & 120 at 10,000 & Nm at rpm \\
Phase voltage limit & 346 & Vpeak \\
Input phase current & 550 & Apeak \\
Saliency ratio $\mathrm{L}_{\mathrm{q}} / \mathrm{L}_{\mathrm{d}}$ & $1.4 \& 2$ & - \\
\hline
\end{tabular}

\subsection{Analysis of Design Parameters Using Output Equation}

Figure 1a,b shows the torque characteristics resulting from the operation of MTPA (maximum torque per ampere) at the rated speed. The black or gray dotted line shows the parameter combination that satisfies $420 \mathrm{Nm}$ at the rated speed. If the saliency ratio $\mathrm{L}_{\mathrm{q}} / \mathrm{L}_{\mathrm{d}}$ is large, the inductance that satisfies a torque of $420 \mathrm{Nm}$ in the same no-load flux linkage decreases. 


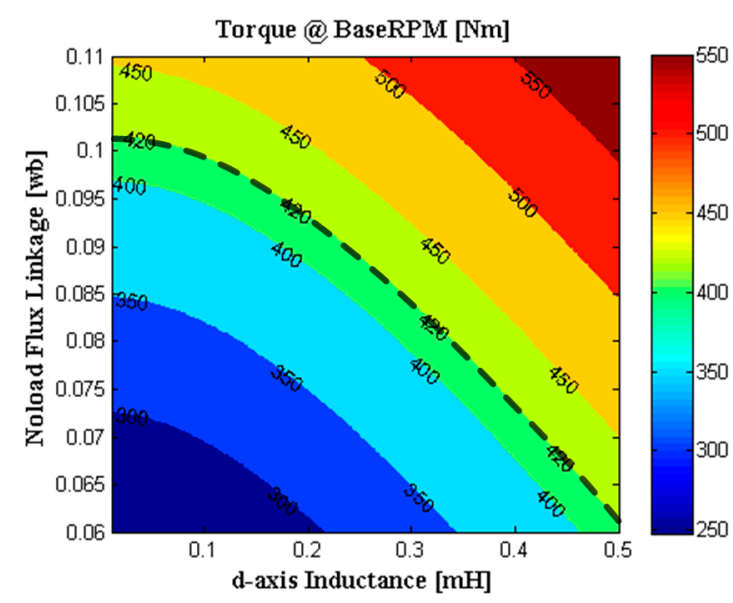

(a) a saliency ratio of 1.4

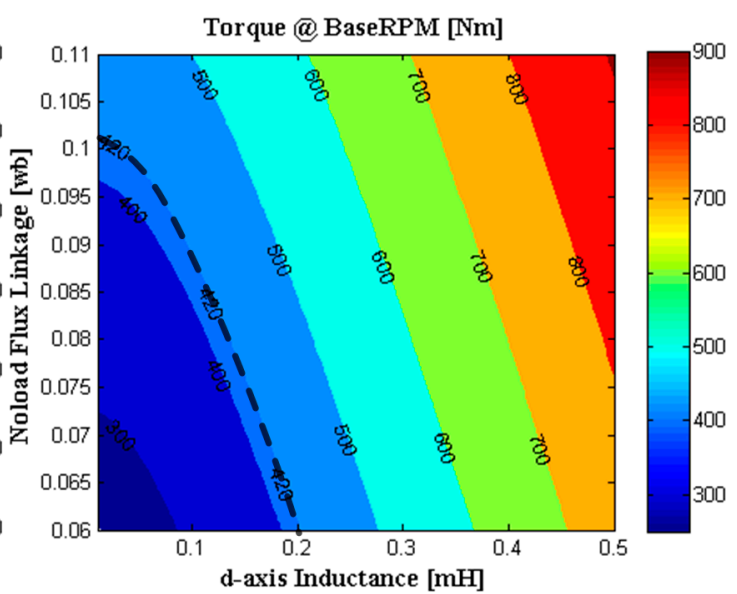

(b) a saliency ratio of 2.0

Figure 1. Torque @ rated-speed.

Figure 2a,b shows the voltage characteristics at the rated speed. If the salience ratio is 1.4 , the operation is impossible at a rated speed exceeding the voltage limit of 346 Vpeak when the no-load flux linkage of the parameter combination is approximately $0.8 \mathrm{wb}$ or smaller. On the other hand, if the saliency ratio is 2 , the operation is possible with all parameter combinations. Figure $3 \mathrm{a}, \mathrm{b}$ shows the power-factor characteristics at the rated speed. The power-factor map does not show any significant differences depending on the saliency ratio. However, with the parameter combination that satisfies the rated torque, as the flux linkage decreases, the power factor decreases more rapidly when the saliency ratio is 2 than when it is 1.4 .

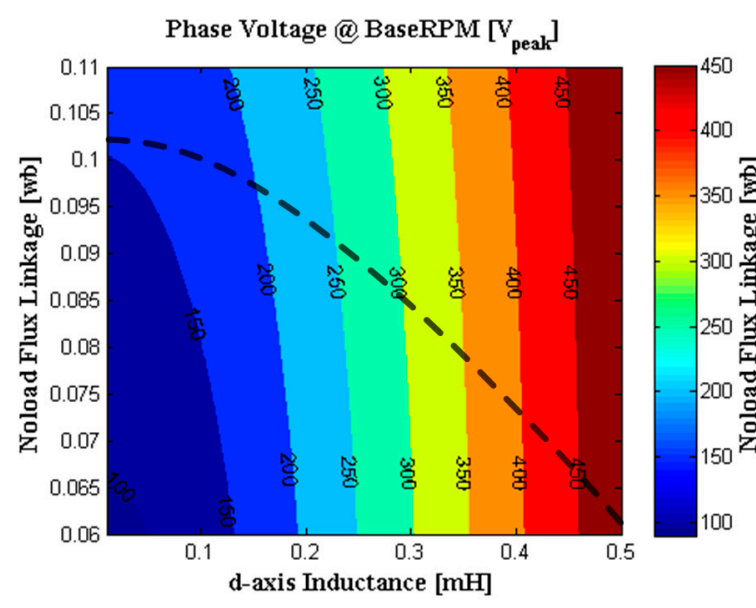

(a) a saliency ratio of 1.4

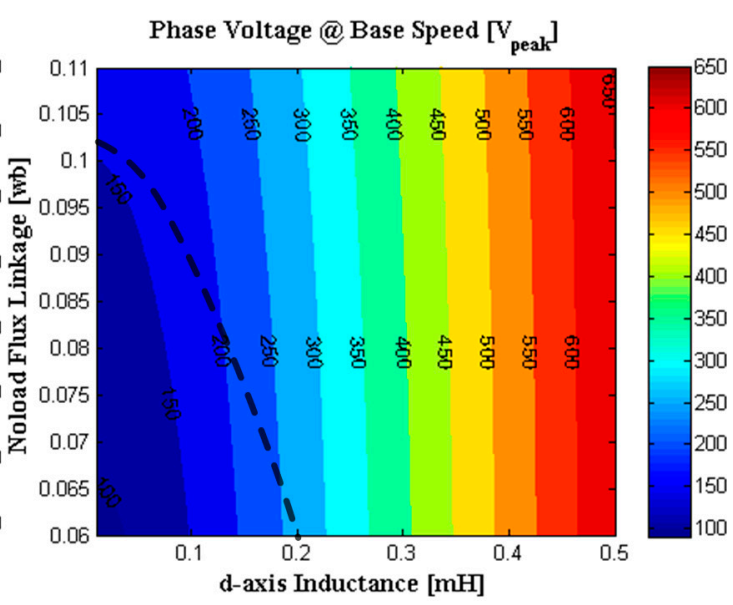

(b) a saliency ratio of 2.0

Figure 2. Voltage @ rated-speed.

Analysis of the parameters at the rated speed revealed that a larger no-load flux linkage and lower induction yield a greater increase in the power factor and a greater reduction in the induced voltage. Additionally, the changes in the power factor and the induced voltage resulting from the change in the flux linkage are greater when the salience ratio is smaller. Thus, at the rated speed, a large no-load flux linkage and saliency ratio and low inductance yield a suitable motor parameter for a high-power factor. 


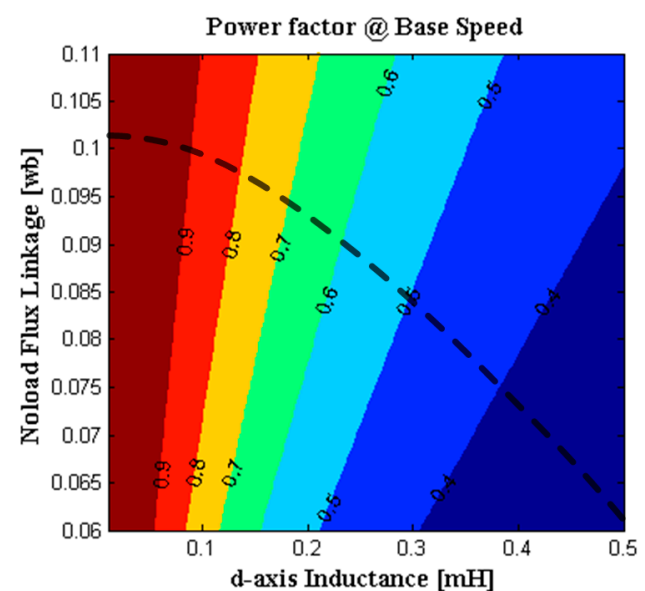

(a) a saliency ratio of 1.4

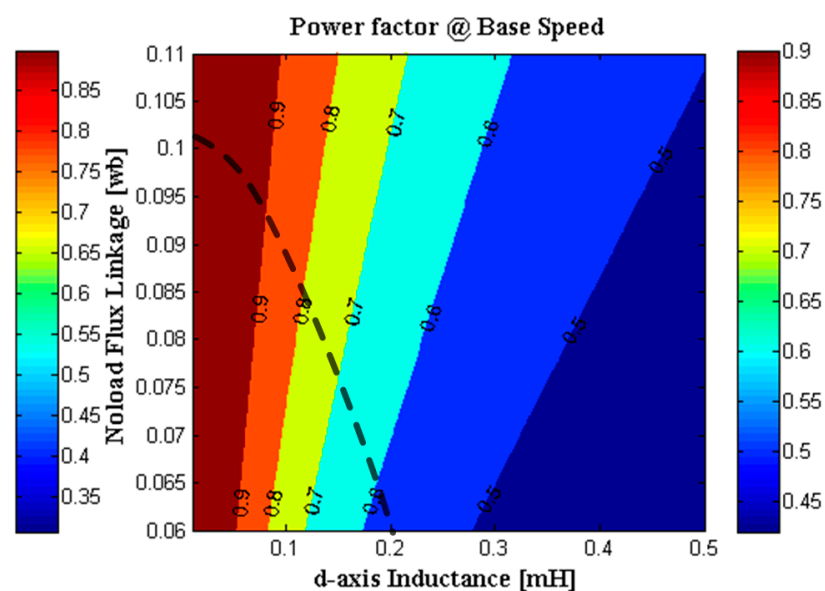

(b) a saliency ratio of 2.0

Figure 3. Power factor @ rated-speed.

At the maximum speed of 10,000 rpm, MTPA operation, flux-weakening operation, and MTPV operation can be performed, depending on the induced voltage, the M point, and the load condition. In this study, maximum torque was generated while satisfying the voltage and current limits by conducting a suitable operation according to the parameter combinations. Figure $4 \mathrm{a}, \mathrm{b}$ shows the torque characteristics at the maximum speed. The area surrounded by the closed curve of black and gray dotted lines represents the parameter combination generating the target torque or greater at the maximum speed, and the other dotted line represents the parameter combination that satisfies the rated torque at the rated speed. To generate the maximum torque at the maximum speed while satisfying the output characteristics of the rated speed, a motor should be designed with parameters corresponding to the intersection of the two areas.

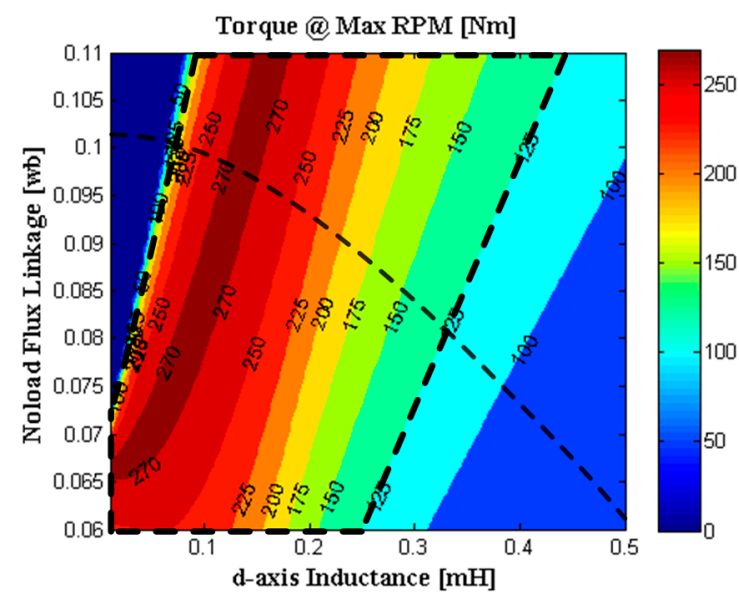

(a) a saliency ratio of 1.4

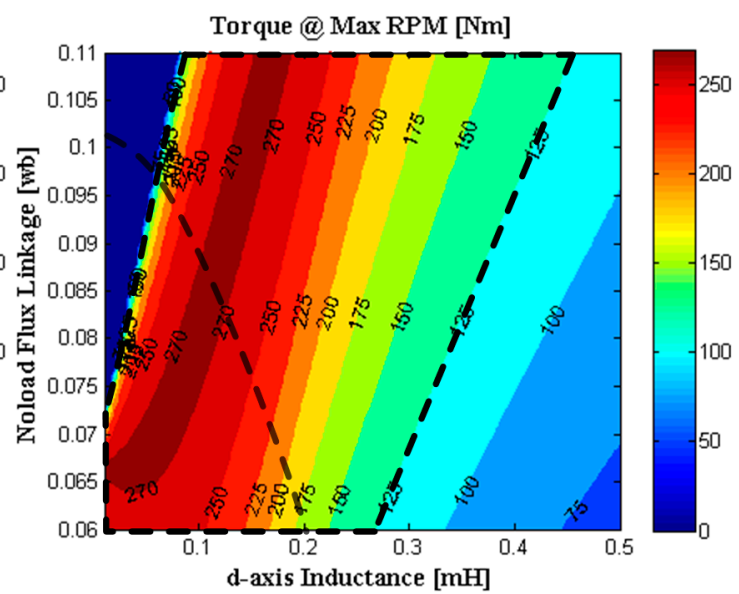

(b) a saliency ratio of 2.0

Figure 4. Torque @ maximum-speed.

Figure $5 \mathrm{a}, \mathrm{b}$ shows the voltage characteristics at the maximum speed. As a result of conducting a suitable operation in accordance with the parameter combinations, it can be seen that the induced voltage is within the voltage limit for most of the parameter combinations. However, the operation is impossible at the maximum speed in the top-left part, where $L_{d}$, is too small compared with $\lambda_{\text {pm }}$, as the phase-induced voltage exceeds the voltage limit of 346 Vpeak because flux-weakening control is impossible. Figure $6 \mathrm{a}, \mathrm{b}$ show the power-factor characteristics at the maximum speed. With the parameter combinations that satisfy the rated torque at the rated speed, the power factor increases up to a certain 
$\lambda_{\mathrm{pm}}$, as in the case of the power-factor characteristics of the rated speed, and rapidly decreases above that, creating an area where operation is impossible.

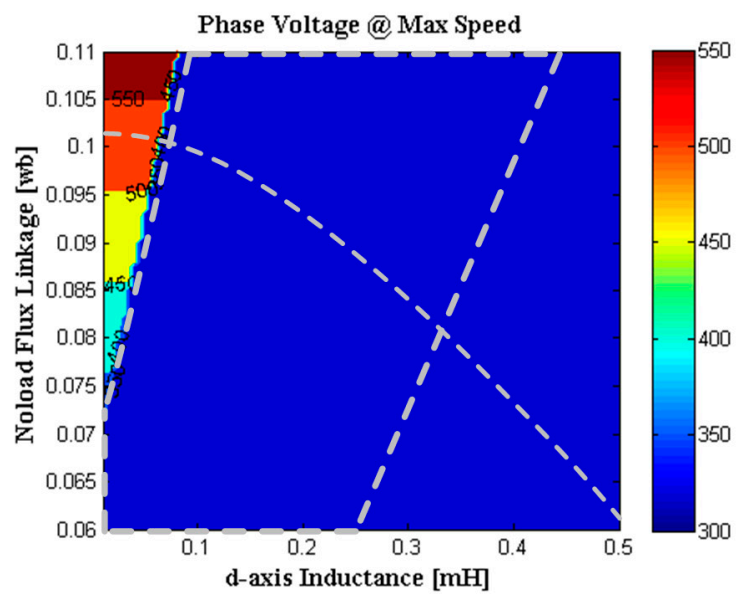

(a) a saliency ratio of 1.4

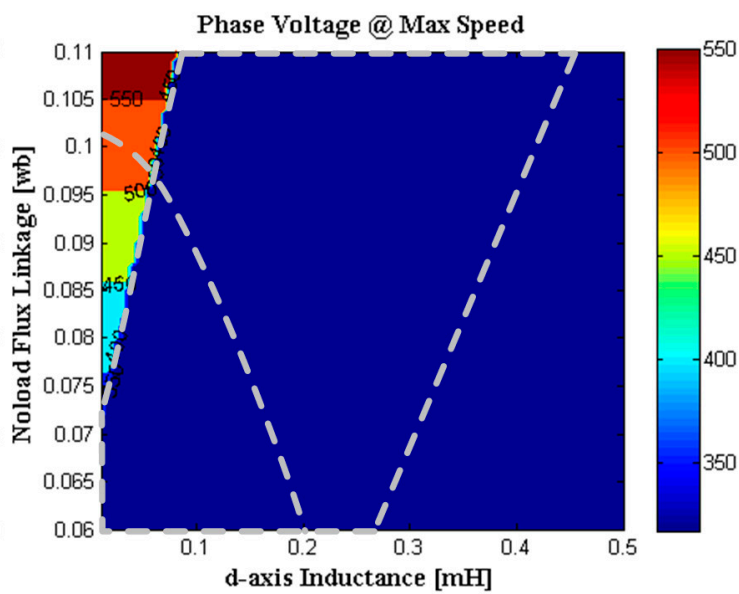

(b) a saliency ratio of 2.0

Figure 5. Voltage @ maximum-speed.

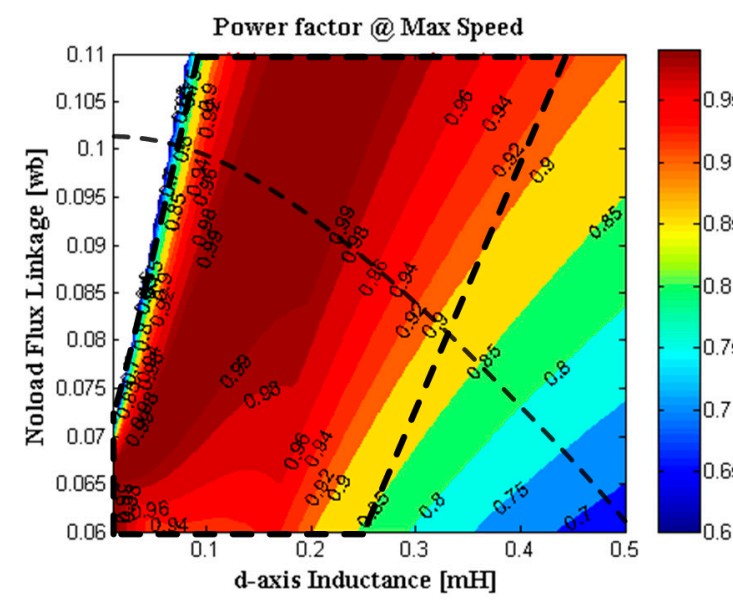

(a) a saliency ratio of 1.4

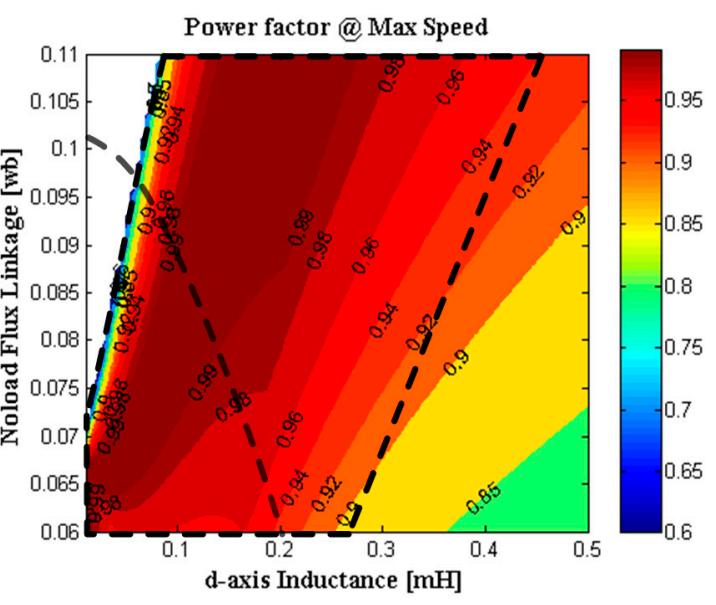

(b) a saliency ratio of 2.0

Figure 6. Power factor @ maximum-speed.

Similarly, in the case of a traction motor for HEVs/EVs, a parameter combination exists for which operation is impossible at a high speed, as the induced voltage exceeds the voltage limit because of the wide operating range. Whether the operation is possible under a light load depending on the parameter combination at the maximum speed must be checked, and the output characteristics at not only the maximum torque but also the rated torque of $120 \mathrm{Nm}$ at the maximum speed must be analyzed. Thus, in the case of a traction motor for HEVs/EVs, an analysis at the maximum speed must be performed differently from that at the rated speed.

\subsection{Analysis and Determination of Design Parameters Using Voltage-Parameter Map (VP-Map)}

As previously shown, numerous parameter combinations generate the target torque of $120 \mathrm{Nm}$ or greater at the maximum speed while satisfying the rated-speed target torque of $420 \mathrm{Nm}$. It was previously explained that owing to the characteristics of the traction motor for HEVs/EVs, an analysis at the maximum speed must be performed differently from that at the rated speed. 
To analyze the output characteristics at the maximum speed, the $d-q$ voltage equation explained in the Section 2 can be expressed in the form of a vector, as follows [22,23]:

$$
\overrightarrow{\mathrm{V}}_{0}=\omega\left(\mathrm{L}_{\mathrm{d}} \mathrm{i}_{\mathrm{d}}+\lambda_{\mathrm{pm}}\right) \overrightarrow{\mathrm{q}}-\omega\left(\mathrm{L}_{\mathrm{q}} \mathrm{i}_{\mathrm{q}}\right) \overrightarrow{\mathrm{d}}
$$

Here, $\vec{V}_{0}$ is the induced voltage vector, excluding the resistance drop, and $\vec{d}$ and $\vec{q}$ are the $\mathrm{d}$-q-axis unit vector.

The right side of Equation (4) can be divided into three sub-terms, as follows:

$$
\overrightarrow{\mathrm{V}}\left(\mathrm{L}_{\mathrm{d}}\right)=\omega \mathrm{L}_{\mathrm{d}} \mathrm{i}_{\mathrm{d}} \overrightarrow{\mathrm{q}}, \overrightarrow{\mathrm{V}}\left(\mathrm{L}_{\mathrm{q}}\right)=-\omega \mathrm{L}_{\mathrm{q}} \mathrm{i}_{\mathrm{q}} \overrightarrow{\mathrm{d}}, \overrightarrow{\mathrm{V}}\left(\lambda_{\mathrm{pm}}\right)=\omega \lambda_{\mathrm{pm}} \overrightarrow{\mathrm{q}}
$$

Here, $\vec{V}\left(L_{d}\right)$ is the voltage vector induced by d-axis inductance, $\vec{V}\left(L_{q}\right)$ is the voltage vector induced by q-axis inductance, and $\vec{V}\left(\lambda_{\mathrm{pm}}\right)$ is the voltage vector induced by the no-load magnetic flux interlinkage.

Two vector diagrams with different parameter combinations are shown in Figure 7a,b. The vector diagram in Figure $7 \mathrm{a}$ is for a parameter combination with a small $\lambda_{\mathrm{pm}}$ and a large $L_{d, q}$, and that in Figure $7 b$ is for a parameter combination with a large $\lambda_{p m}$ and a small $\mathrm{L}_{\mathrm{d}, \mathrm{q}}$. These vector diagrams comprise a $\mathrm{d}$-axis in place of the $\mathrm{x}$-axis, a q-axis in place of the y-axis, and the three voltage vector components of (2). A limiting circle that indicates the voltage limit and a current-vector combination that satisfies the target torque are shown in Figure 7a,b, respectively.

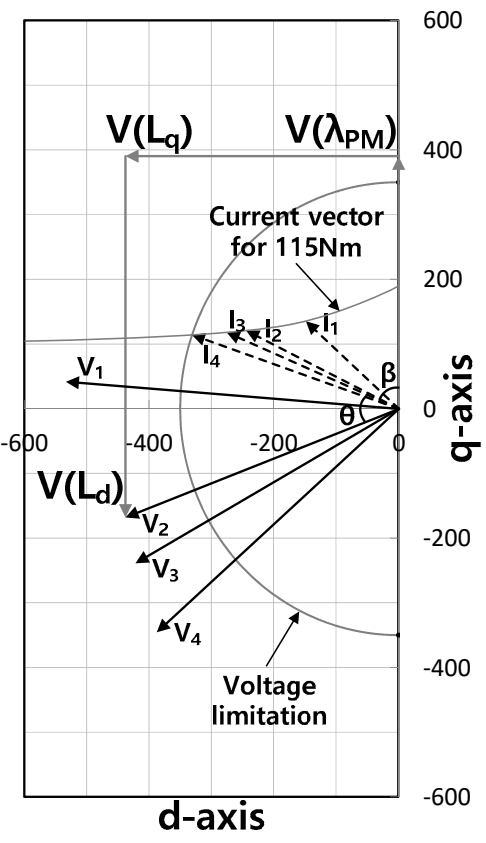

(a) Parameter Combination Example 1

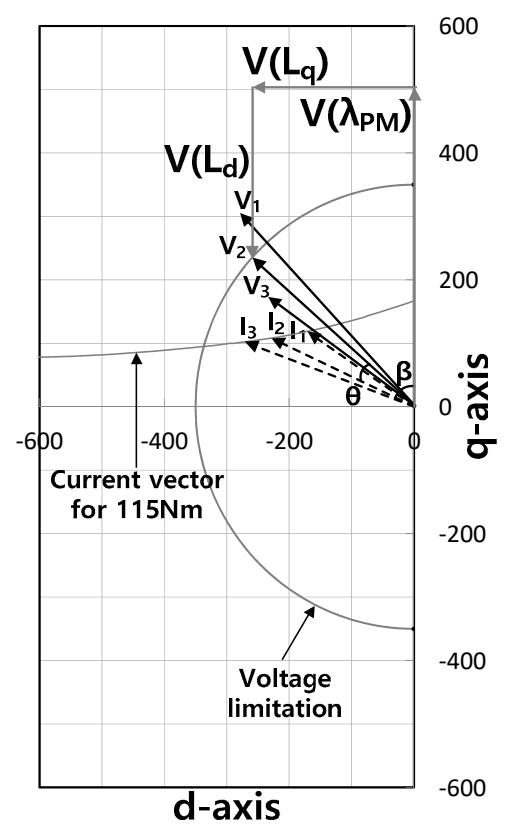

(b) Parameter Combination Example 2

Figure 7. Example of the d-q-axis vector diagram at 10,000 rpm.

Figure $7 \mathrm{a}$ shows the vector diagram for a case where the induced voltage is not satisfied, and Figure $7 \mathrm{~b}$ shows the vector diagram for a case where the induced voltage is satisfied. Among the many current vectors shown in Figure $7 \mathrm{a}, \mathrm{I}_{2}$ has the lowest induced voltage. The voltage induced by $I_{2}$ is $V_{2}$, and the angle between the two vectors can be described as the power-factor angle if the resistance drop is ignored. The angle $\beta$ between the $\mathrm{q}$-axis and the current vector is the current phase angle. A current vector that satisfies the voltage limit exists in Figure $7 \mathrm{~b}$ differently from Figure $7 \mathrm{a}$. Among the induced voltages, the voltage induced by the current vector $\mathrm{I}_{2}$ almost equals the voltage limit. As the current 
is the lowest at this time, this current vector is suitable for maximum-speed operation because its efficiency characteristics are most advantageous.

The vector diagram of Figure 7 indicates that although a high voltage of $\vec{V}\left(\lambda_{\mathrm{pm}}\right)$ is induced by the PM, the total voltage of the q-axis is reduced by the $\vec{V}\left(L_{d}\right)$ resulting from the $d$-axis inductance, which is a flux-weakening control characteristic. $\vec{V}\left(L_{d}\right)$ is the voltage vector related to the flux-weakening control that lowers the voltage induced by the PM, and that in Figure 7a is larger than that in Figure $7 \mathrm{~b}$. As $\vec{V}\left(\lambda_{\mathrm{pm}}\right)$ in (a) is smaller than that in (b), the total voltage of the q-axis in Vector Diagram (a) shows a negative value. Although such a result means that the flux-weakening control is better performed in (a) than in (b), while (a) fails to satisfy the voltage limit, (b) satisfies the voltage limit. This is because the $\vec{V}\left(L_{q}\right)$ of Figure 7a has exceeded the voltage limit regardless of the flux-weakening control performance. Whether operation is possible at the maximum speed is determined by the $\vec{V}\left(L_{q}\right)$ in Figure 7 rather than by the flux-weakening control performance.

Figure 8 shows the results of analyzing parameter combinations $1-3$ by using the previously explained vector diagram to analyze the output characteristics at the maximum speed as the high-speed torque characteristics when the saliency ratio is 2 in the previous paragraph.

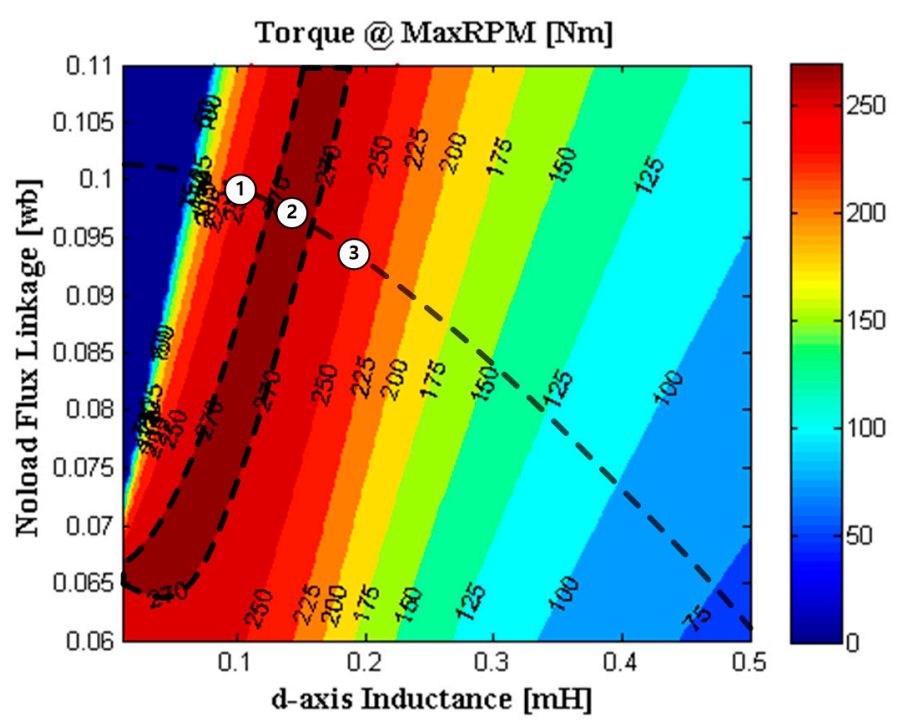

Figure 8. Parameters for characteristic analysis at $10,000 \mathrm{rpm}$.

Each parameter and the output characteristics at the maximum speed are shown in Table 2. At the rated speed, the power-factor characteristics of Point 1 are the best. However, Table 2 shows that at the maximum speed, the power-factor characteristics of Points 2 and 3 are the best at the maximum torque and the rated torque, respectively. Although the power factor and torque characteristics of Points 1 and 3 at the maximum torque are almost similar, there is a large difference in the input current and power-factor characteristics at the rated torque. To analyze this result, the $\mathrm{d}-\mathrm{q}$ vector diagrams at the maximum torque and at the rated torque are examined, as shown in Figures 9 and 10, respectively. In the case of Figure 9a, the voltage vector is closer to the q-axis than to the d-axis, as the flux linkage is large and the inductance is small. For Point 2, Figure $9 \mathrm{~b}$ and Table 3 show that the power factor is close to 1 because the current and the voltage vectors are close to each other. Figure $9 \mathrm{c}$ shows a decreased flux linkage and an increased inductance compared with Figure 9a, making the voltage vector almost parallel with the d-axis. As the d-axis currents of Figure 9a-c are almost equal, the flux-weakening control performance of (c), which has the largest $\vec{V}\left(L_{d}\right)$, can be said to be the best. 
Table 2. Parameters for analysis and output characteristics at $10,000 \mathrm{rpm}$.

\begin{tabular}{|c|c|c|c|c|c|}
\hline \multicolumn{2}{|c|}{ Specification } & Point 1 & Point 2 & Point 3 & Unit \\
\hline \multicolumn{2}{|c|}{$\lambda_{\mathrm{pm}}$} & 0.0995 & 0.0975 & 0.094 & $\mathrm{~Wb}$ \\
\hline \multicolumn{2}{|c|}{$\mathrm{L}_{\mathrm{d}}$} & 0.103 & 0.142 & 0.191 & $\mathrm{mH}$ \\
\hline \multicolumn{2}{|c|}{$\mathrm{L}_{\mathrm{q}}$} & 0.206 & 0.285 & 0.383 & $\mathrm{mH}$ \\
\hline \multirow{4}{*}{$\begin{array}{l}\text { Maximum } \\
\text { Torque }\end{array}$} & $\mathrm{I}, \beta$ & $550,66.2$ & $550,67.2$ & $550,71.8$ & $A_{\text {peak }}, \operatorname{deg} E$ \\
\hline & Torque & 252 & 271.2 & 249.9 & $\mathrm{Nm}$ \\
\hline & $\begin{array}{l}\text { Induced } \\
\text { voltage }\end{array}$ & 345.8 & 344.2 & 345.5 & $V_{\text {peak }}$ \\
\hline & PF & 0.925 & 1 & 0.918 & - \\
\hline \multirow{4}{*}{$\begin{array}{l}\text { Rated } \\
\text { Torque }\end{array}$} & $\mathrm{I}, \beta$ & $387,72.4$ & $307,67.8$ & $262,63.8$ & $A_{\text {peak }}, \operatorname{deg} E$ \\
\hline & Torque & 120.7 & 120 & 120.6 & $\mathrm{Nm}$ \\
\hline & $\begin{array}{c}\text { Induced } \\
\text { voltage }\end{array}$ & 345.8 & 345.1 & 345.8 & $V_{\text {peak }}$ \\
\hline & PF & 0.63 & 0.791 & 0.929 & - \\
\hline
\end{tabular}

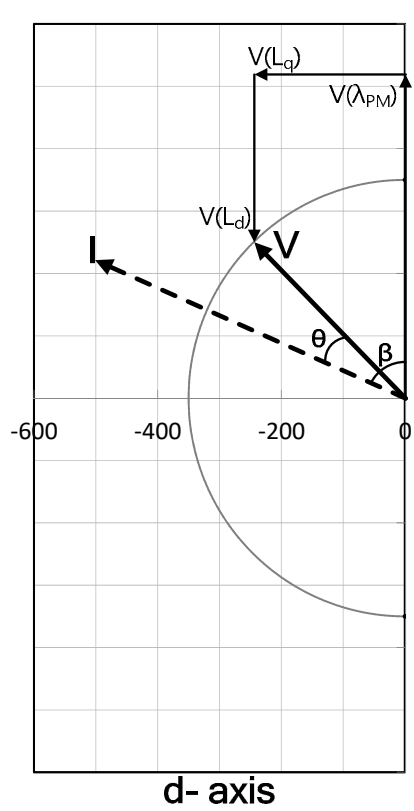

(a) Point1

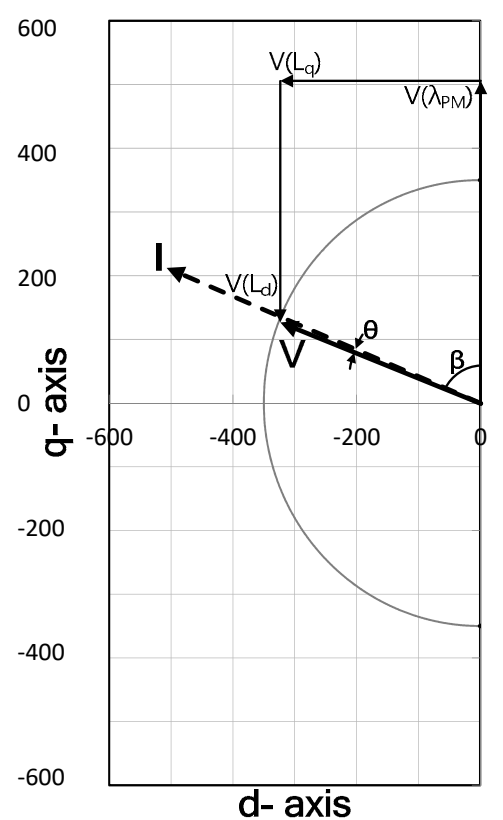

(b) Point2

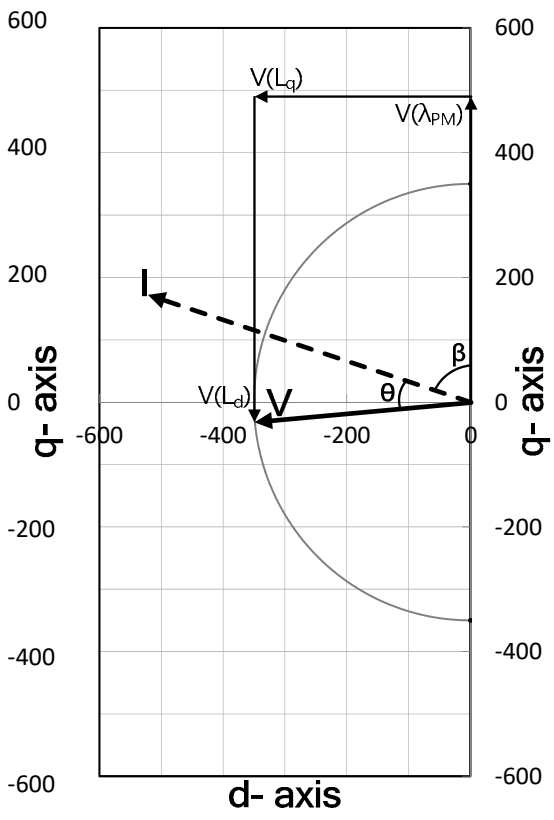

(c) Point3

Figure 9. A vector diagram of the maximum torque about each parameter at 10,000 rpm. 


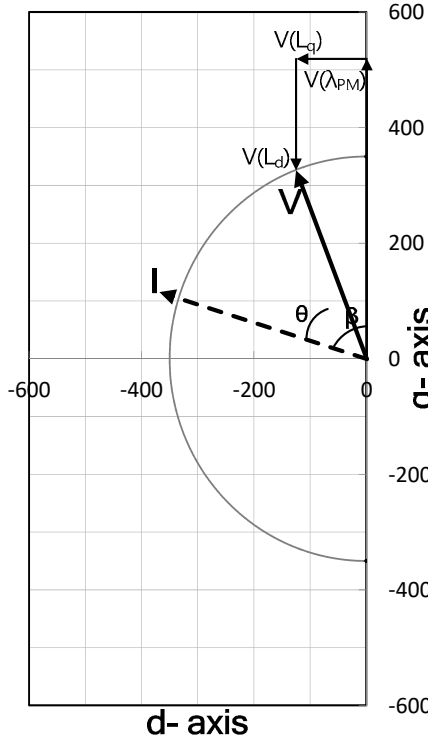

(a) Point1

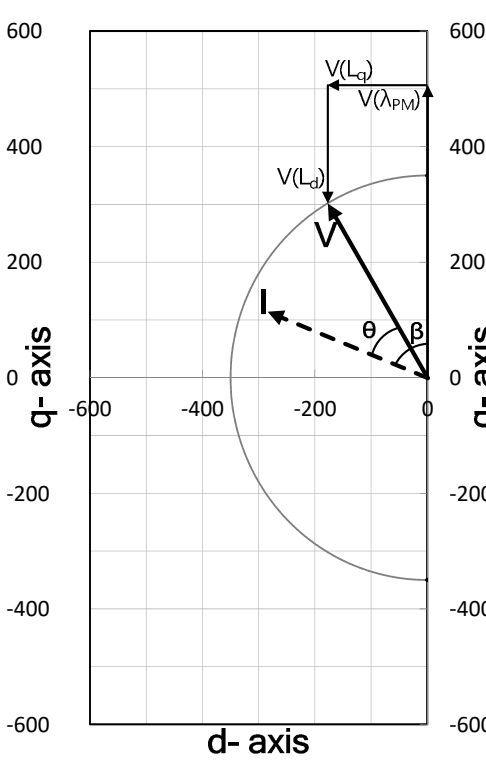

(b) Point2

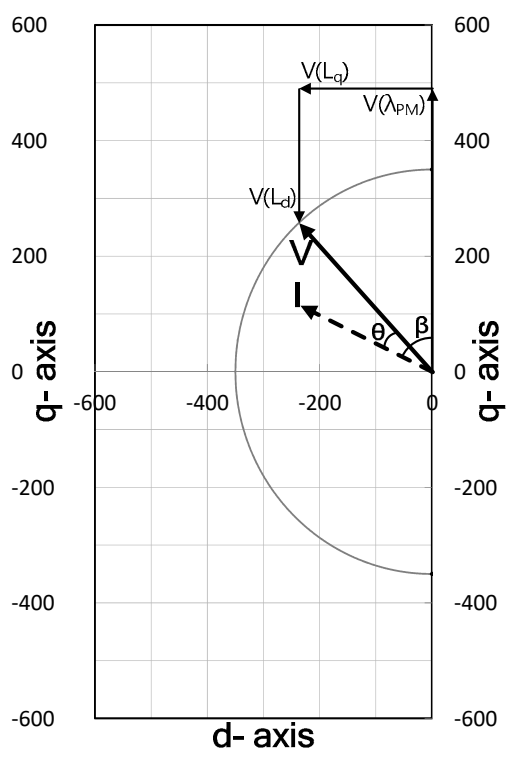

(c) Point3

Figure 10. A vector diagram of the rated torque about each parameter at $10,000 \mathrm{rpm}$.

Table 3. Shape specifications for each model.

\begin{tabular}{cccc}
\hline Laminate Length $(\mathbf{m m})$ & Magnet Width $(\mathbf{m m})$ & Magnet Angle $(\mathrm{deg})$ & Pole Arc Rate $(\%)$ \\
\hline 180 & 16.2 & 30 & 75 \\
160 & 20.8 & 56 & \\
140 & 26.3 & 64.5 & \\
\hline
\end{tabular}

The voltage and current vectors at the time when the rated torque is generated at the maximum speed are shown in Figure 10. The rated torque decreases by $\vec{V}\left(L_{q}\right)$ as the q-axis current decreases from the maximum torque, and the voltage vector approaches the q-axis. The greatest difference between Figure $10 \mathrm{a}-\mathrm{c}$ is that the size of the current vector decreases as the point moves from (a) to (c). The efficiency characteristics of (c), for which the current is the smallest when the rated torque is generated, is most advantageous for generating the same rated torque. The phase difference in the voltage and current of the vector diagram indicates that the power factor of (c) is higher than those of (a) and (b).

Although the q-axis currents, which are the torque currents of Figure $10 \mathrm{a}-\mathrm{c}$, do not exhibit a large difference, the d-axis currents for flux weakening differ considerably. The levels of $\vec{V}\left(L_{d}\right)$, i.e., which represents the flux weakening at the rated torque, do not exhibit a large difference; however, the case of (c), for which the inductance is the highest, exhibits the smallest d-axis current, which is the flux-weakening current. As the $\vec{V}\left(\lambda_{\text {pm }}\right)$ of Figure 10c is smaller than those of (a) and (b), the required for flux weakening becomes smaller than those for (a) and (b) as the voltage vector approaches the q-axis. Thus, the input current of (c) becomes smaller than those of (a) and (b) at torques smaller than the rated torque.

The power factor and the maximum torque characteristics improve up to a certain flux linkage when the maximum torque is generated at the maximum speed, and above this value, the characteristics deteriorate, making operation impossible. However, when the rated torque is generated at the maximum speed, the more the flux linkage grows and the inductance decreases, the more disadvantageous the flux-weakening characteristics become. Thus, at the maximum speed, the parameters should be determined by considering not only the characteristics of the maximum input current but also the characteristics under the rated load or lower. To analyze the characteristics under all loads at the maximum 
speed, the current and the current phase angle that satisfy the voltage limit under each load should be known.

In this study, to analyze the characteristics under each load at the maximum speed by determining these two values, the VP-Map, which applies the $\mathrm{d}-\mathrm{q}$ vector diagram previously explained, is employed.

Figure 11 shows the $d-q$ vector diagram with parameters of $\lambda_{p m}, L_{d}$, and $L_{q}$ for currents of $I_{1}$ and $I_{2}$. $I_{1}$ and $I_{2}$ are the current vectors that satisfy the voltage limit at the maximum speed, and the levels of their torques differ. To determine $i_{d}$ and $i_{q}$, the voltage vector $\mathrm{V}$ can be expressed in three voltage components as follows, by putting it in order as the $\mathrm{d}$-q-axis components:

$$
\mathrm{V}_{\mathrm{d}}=\mathrm{V} \sin \delta=\overrightarrow{\mathrm{V}}\left(\mathrm{L}_{\mathrm{q}}\right), \mathrm{V}_{\mathrm{d}}=\mathrm{V} \sin \delta=\overrightarrow{\mathrm{V}}\left(\mathrm{L}_{\mathrm{q}}\right), \mathrm{V}_{\mathrm{q}}=\mathrm{V} \cos \delta=\overrightarrow{\mathrm{V}}\left(\lambda_{\mathrm{pm}}\right)+\overrightarrow{\mathrm{V}}\left(\mathrm{L}_{\mathrm{d}}\right)
$$

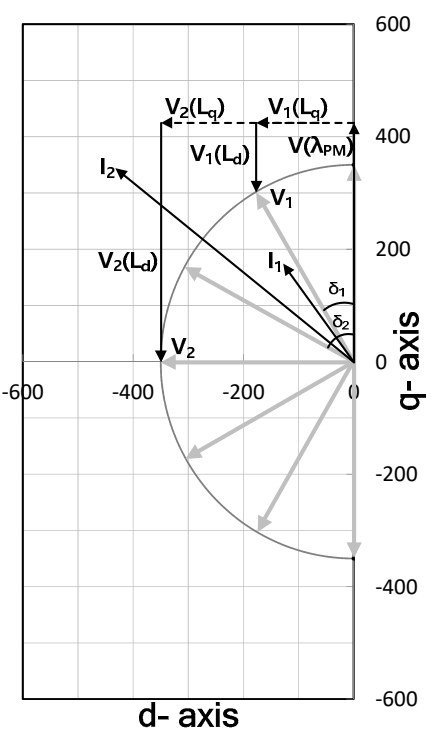

Figure 11. Principles of the VP-Map.

If $\lambda_{\mathrm{pm}}, \mathrm{L}_{\mathrm{d}}$, and $\mathrm{L}_{\mathrm{q}}$ at the maximum speed and the phase angle $\delta$ of the voltage are known, $i_{d}$ and $i_{q}$ can be determined using the relationship in (3). $i_{d}$ and $i_{q}$ at this time are the values for which the induced voltage is equal to the voltage limit, and all the current combinations that satisfy the voltage limit at a high speed can be obtained by determining $\mathrm{i}_{\mathrm{d}}$ and $\mathrm{i}_{\mathrm{q}}$ while increasing $\delta$ from $0 \operatorname{degE}$ to $180 \operatorname{degE}$. The $\mathrm{x}$-axis in Figure 12 indicates the angle of the voltage vector, and the $y$-axis indicates the flux linkage. Figure 12a,b show the $\mathrm{d}$-q-axis inductance that satisfies the rated torque at the rated speed. The values are the same depending on the angle of the voltage vector. These are the values of $\lambda_{\mathrm{pm}}$, $\mathrm{L}_{\mathrm{d}}$, and $\mathrm{L}_{\mathrm{q}}$ for analysis of the maximum-speed characteristics while satisfying the output characteristics at the rated speed and, as the values remain the same regardless of the voltage phase angle, which is indicated by the x-axis, it is expressed as flux linkage only in the later maps. That is, although only the flux linkage is indicated on the y-axis in the later maps, it represents the parameter combination of $\lambda_{\mathrm{pm}}, \mathrm{L}_{\mathrm{d}}$, and $\mathrm{L}_{\mathrm{q}}$ that satisfies the rated torque at the rated speed. Such a map, wherein the $x$-axis represents the angle of the voltage vector, and the $y$-axis indicates the parameter combination that satisfies the rated torque at the rated speed, is called a VP-Map. Using a VP-Map, the characteristics under all loads that satisfy the voltage limit at a high speed can be determined, making it easy to determine the high-speed characteristics of a motor. Figure 13 shows the current and the current phase angles under all loads that satisfy the voltage limit, and Figure 14 shows the torque and power-factor characteristics of the motor at this time. 


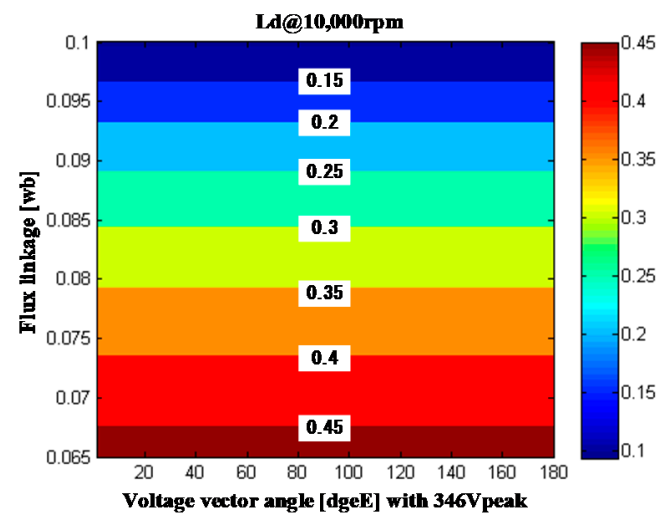

(a) d-axis inductance

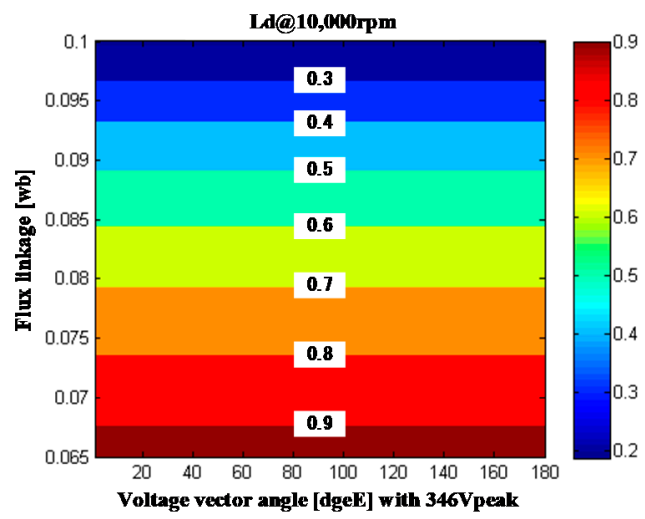

(b) q-axis inductance

Figure 12. $\mathrm{d}-\mathrm{q}$-axis inductance of the VP-Map.

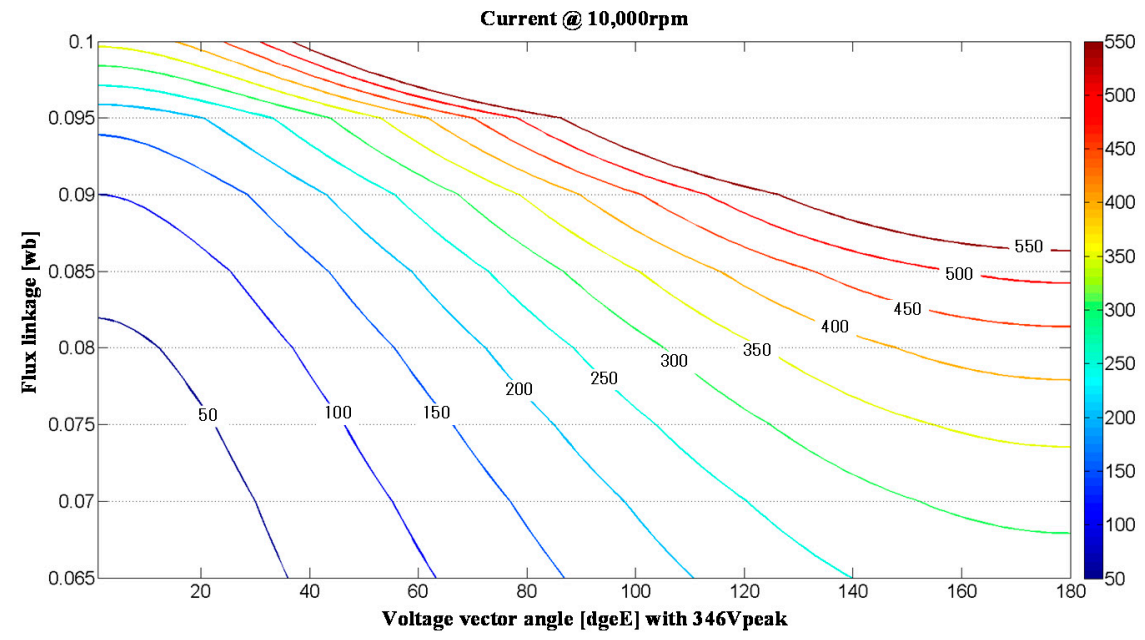

(a) Current

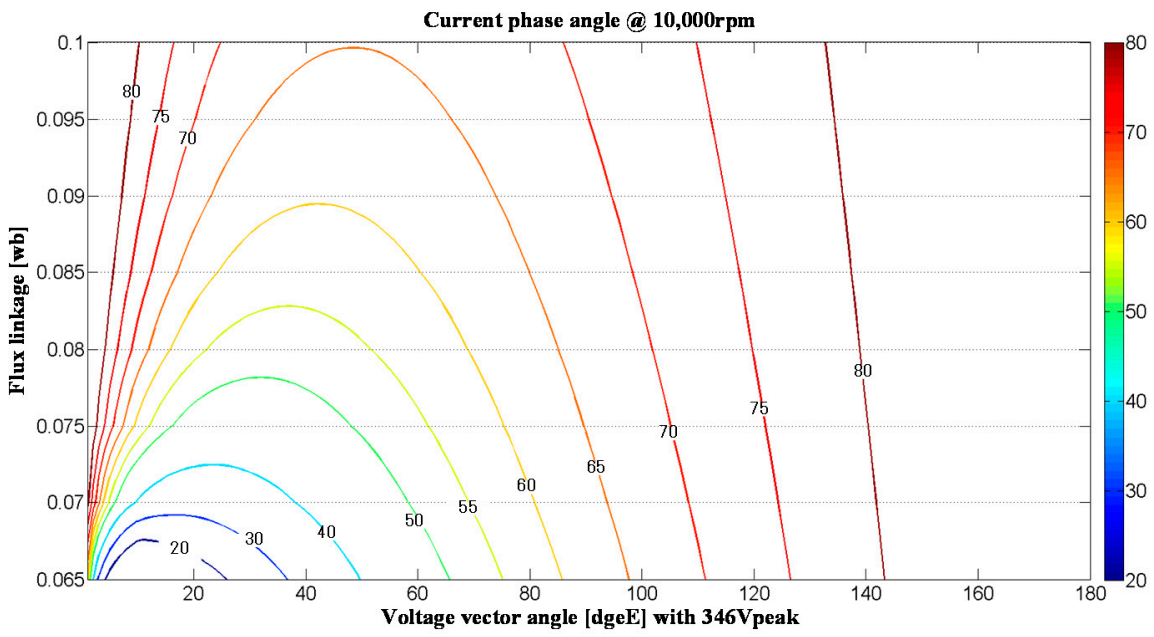

(b) Current phase angle

Figure 13. Current and current phase angle at 10,000 rpm determined using the VP-Map. 


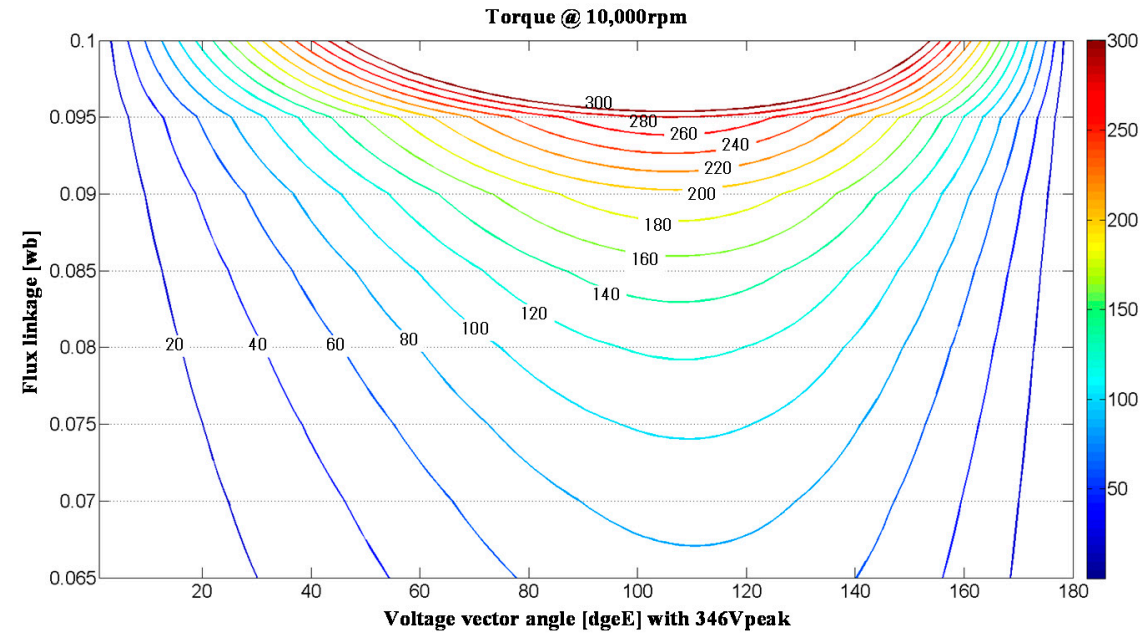

(a) Torque

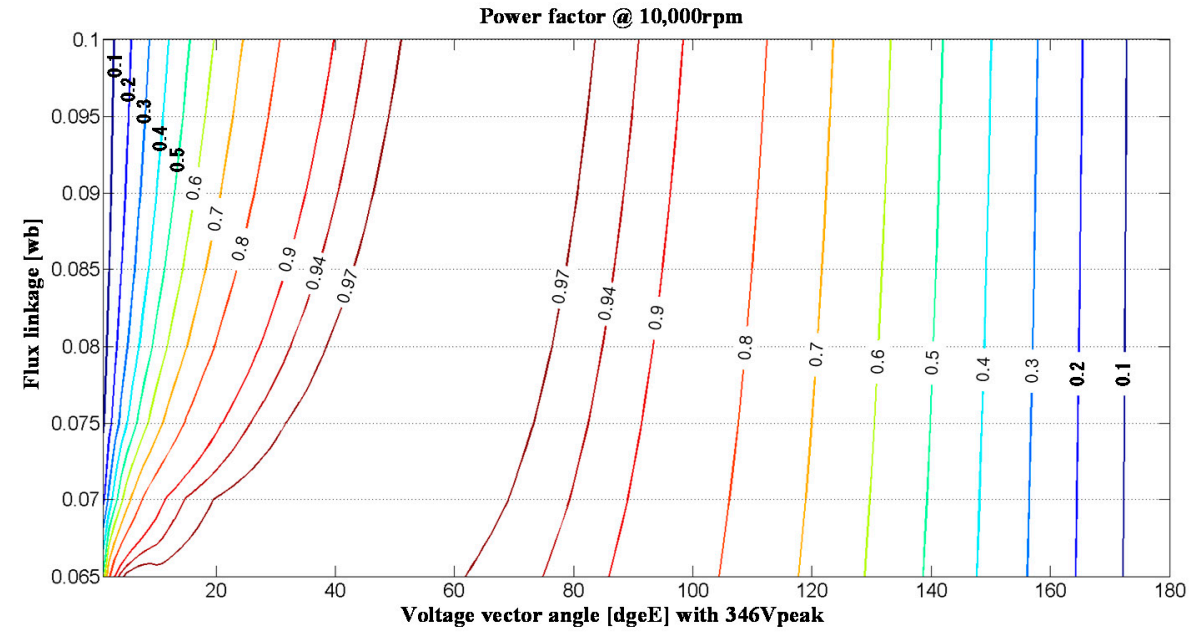

(b) Power factor

Figure 14. Output characteristics at 10,000 rpm determined using the VP-Map.

The dotted line in Figure 15a represents the maximum input current of 550 Apeak, and each black dot represents the maximum torque of each y-axis parameter. Although the maximum torque is generated at the maximum input current when the flux linkage is $0.095 \mathrm{wb}$ or larger, the maximum torque is generated at an input current smaller than the maximum input current when the flux linkage is $0.09 \mathrm{wb}$ or smaller. Thus, the maximum torque that can be generated at the maximum speed can be determined via parameter combination. The area marked with diagonal lines in Figure 15a represents the section in which the current phase angle is larger than $80 \mathrm{degE}$; in this area, the characteristics in the case where the current phase angle is controlled below $80 \mathrm{degE}$ can be determined. With the parameter combination of $0.1 \mathrm{wb}$, a torque not greater than $60 \mathrm{Nm}$ cannot be generated in such a condition. 


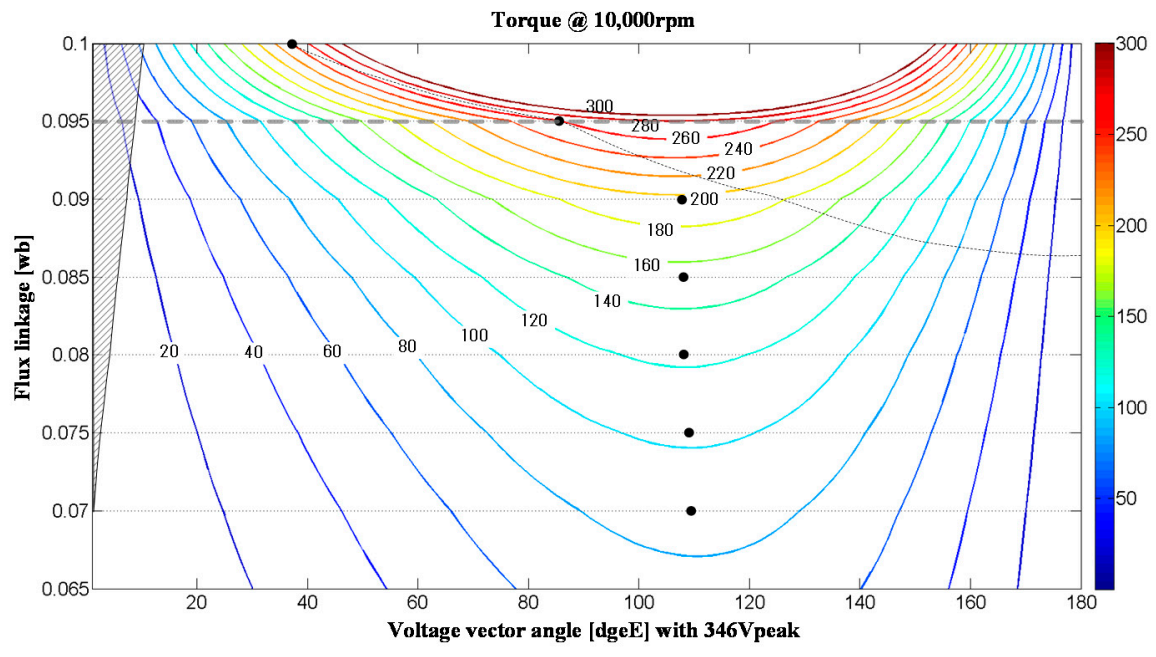

(a) Torque

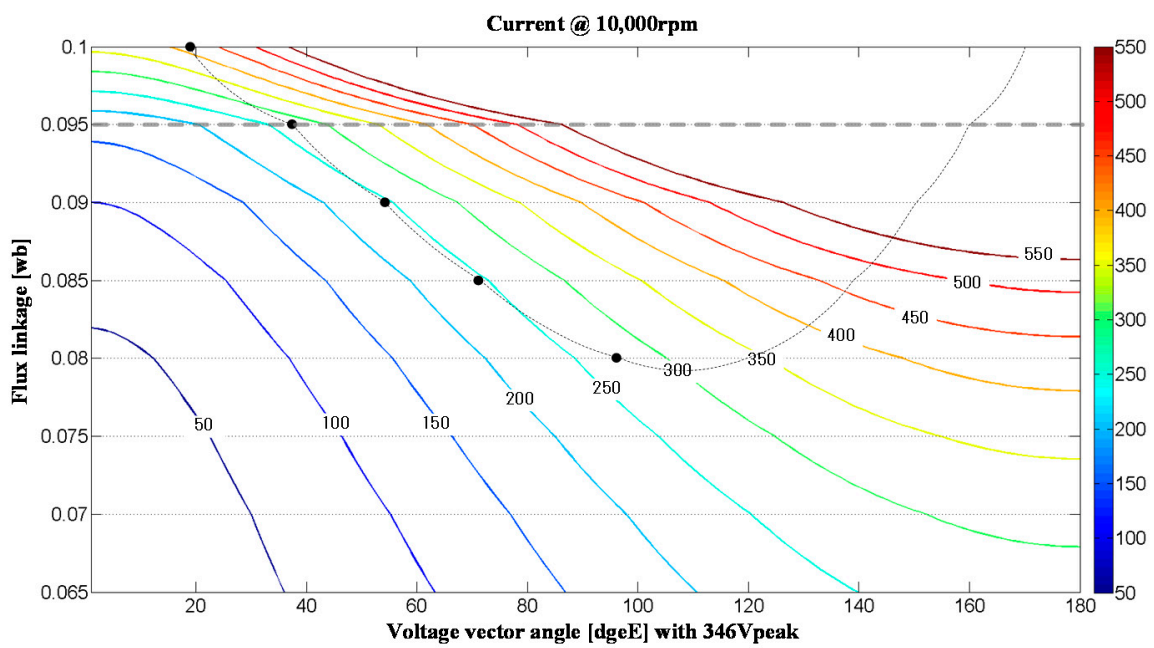

(b) Current

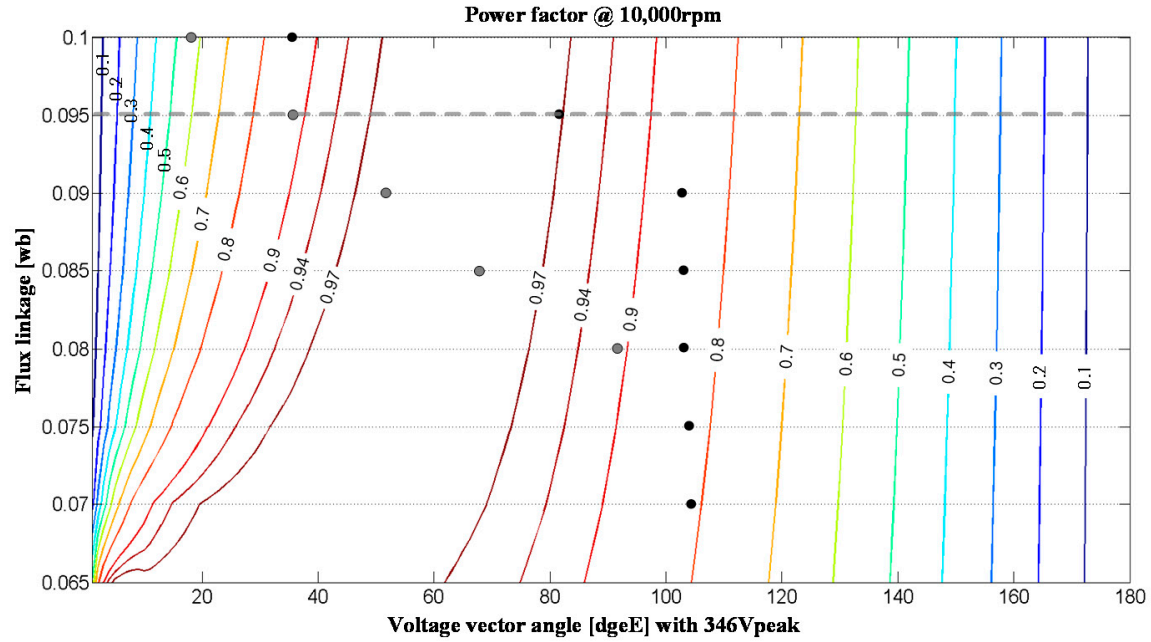

(c) Power factor

Figure 15. Determination of the design parameter using the VP-Map.

The black dotted line in Figure $15 \mathrm{~b}$ represents the rated torque of $120 \mathrm{Nm}$ at the maximum speed, and each black dot represents the intersection point between each y-axis flux linkage and the rated torque. In the case where the flux linkage is between $0.085(\mathrm{wb})$ 
and $0.09(\mathrm{wb})$, a current of torque, and the more the flux linkage grows from $0.095(\mathrm{wb})$, the more the current required for the generation of the rated torque rapidly increases. The current rapidly increases because as the flux linkage increases, the flux-weakening current increases to satisfy the voltage limit.

The black dots in Figure 15c represent the maximum torque at the maximum speed, and the gray dots represent the rated torque at the maximum speed. The power-factor characteristic is the highest for the rated torque, exhibiting a value of 0.97 or higher when the flux linkage is between $0.085(\mathrm{wb})$ and $0.09(\mathrm{wb})$. In the case of the maximum torque, the power factor is the highest when the flux linkage is 0.095 (wb).

The design-parameter combination finally obtained is shown by the gray dotted line in Figure 15, for which the values of $\lambda_{\mathrm{pm}}, \mathrm{L}_{\mathrm{d}}$, and $\mathrm{L}_{\mathrm{q}}$ are $0.095 \mathrm{wb}, 0.1766 \mathrm{mH}$, and $0.353(0.2472) \mathrm{mH}$, respectively. The value inside the parentheses is the q-axis inductance at the rated speed, and the value outside the parentheses is the q-axis inductance at the maximum speed. The design parameters are determined in this manner not only because the power factor is high with these parameters at the rated speed but also because the greatest torque of approximately $260 \mathrm{Nm}$ is generated at the maximum speed, and a torque of $30 \mathrm{Nm}$ or higher, which is a light load, can be generated at the maximum speed. Moreover, the current required for generating the rated torque is not significantly different from 245 Apeak, the lowest case, exhibiting a value of 275 Apeak. Thus, the design parameters suitable for the target HEV are determined by analyzing the torque and the power-factor characteristics at the rated speed, the maximum torque that can be generated using the VP-Map at the maximum speed, the current required for generating the rated torque, and whether the operation is possible under a light load.

\section{Comparative Analysis of Fcpmsm}

Even when the target torque is satisfied at the rated speed and the maximum speed, if the combinations of $\lambda_{\mathrm{pm}}, \mathrm{L}_{\mathrm{d}}$, and $\mathrm{L}_{\mathrm{q}}$ differ, the operational performances of the motors vary. The differences between the operational performances of motors with different parameter combinations were investigated via finite-element analysis. Three models of flux-concentrating motors with different parameter combinations are shown in Figure 16, and the shape data for each model are shown in Table 3. The shape of each rotor was designed to generate the target torque at the rated speed in accordance with the laminate length.

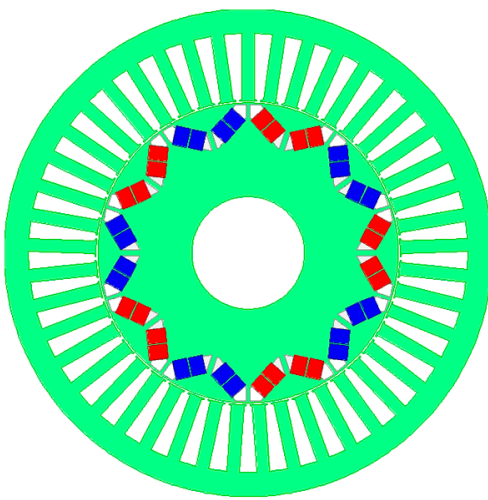

(a) $180 \mathrm{~mm}$

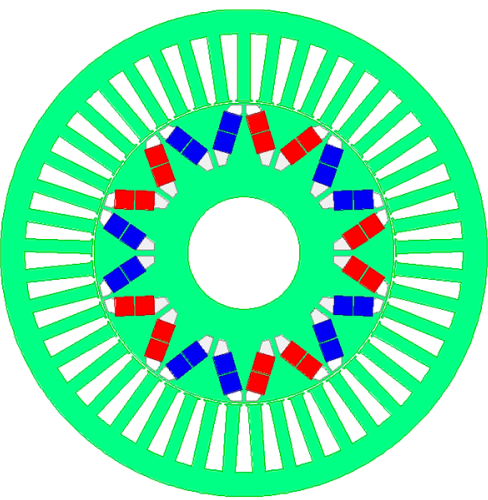

(b) $160 \mathrm{~mm}$

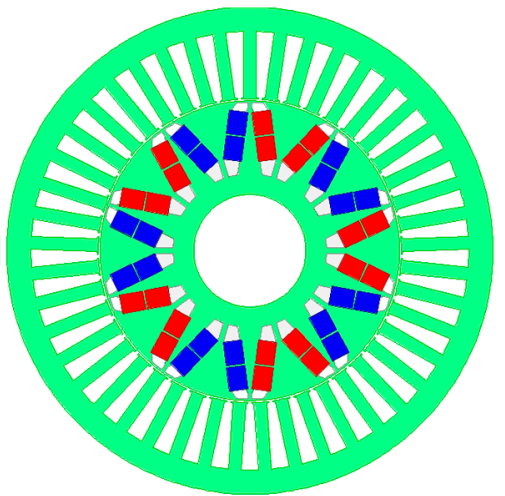

(c) $140 \mathrm{~mm}$

Figure 16. Analysis models for characteristic comparison.

The input for the finite element analysis of each model and the results of the analysis are shown in Table 4. At the rated speed, the analysis was performed according to the current phase angle for MTPA and at the maximum speed according to the current phase angle for flux-weakening control. Figure 17 is the magnetic flux density distribution diagram that is the analysis result under the rated load. Although all three models satisfy 
the target torque both at the rated speed and the maximum speed, the more the laminate length decreases, the more the maximum torque increases, and the induced voltage at the rated speed decreases. According to Table 4, the more the laminate length decreases, the more the copper loss and the core loss decrease. This is because the resistance decreases as the laminate decreases in the case of copper loss, and in the case of core loss, the absolute amount of core where the core loss occurs decreases as the laminate decreases.

Table 4. Input and output characteristics for finite-element analysis of each model.

\begin{tabular}{cccccc}
\hline RPM & Value & $\mathbf{1 8 0} \mathbf{~ m m}$ & $\mathbf{1 6 0} \mathbf{~ m m}$ & $\mathbf{1 4 0} \mathbf{~ m m}$ & Unit \\
\hline & Current & 550 & 550 & 550 & $\mathrm{~A}_{\text {peak }}$ \\
& Phase angle & $40 / 78$ & $35 / 71$ & $30 / 66$ & degE \\
2843 & Torque & $434 / 179$ & $437 / 244$ & $437 / 271$ & Nm \\
$/ 10,000$ & Phase voltage & $231 / 346$ & $206 / 346$ & $184 / 346$ & $\mathrm{~V}_{\text {peak }}$ \\
& Core loss & $962 / 6660$ & $848 / 4893$ & $727 / 4467$ & $\mathrm{~W}$ \\
& Eddy current loss & $3 / 190$ & $2 / 127$ & $2 / 79$ & $\mathrm{~W}$ \\
& Copper loss & 5010 & 4640 & 4271 & $\mathrm{w}$ \\
\hline
\end{tabular}

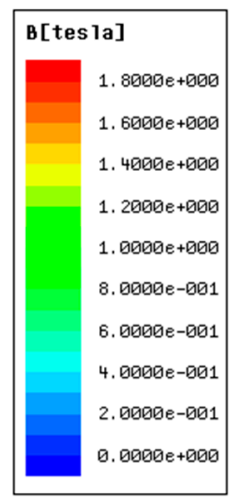

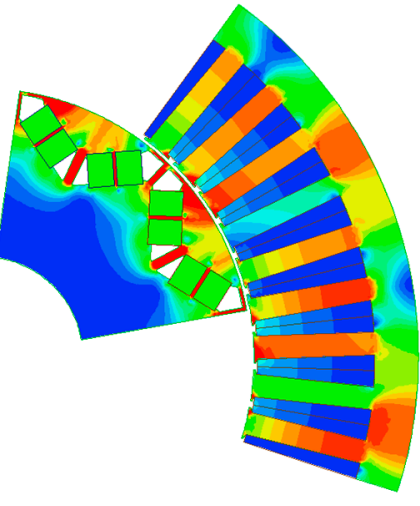

(a) $180 \mathrm{~mm}$

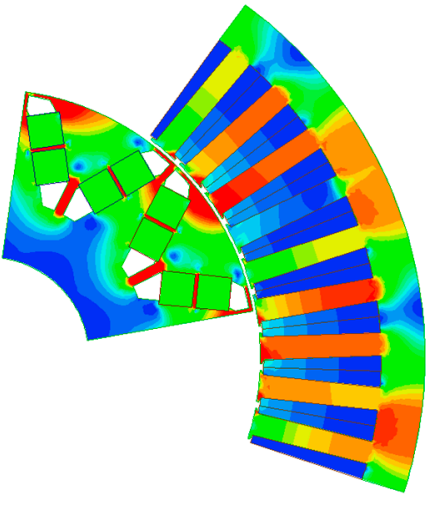

(b) $160 \mathrm{~mm}$

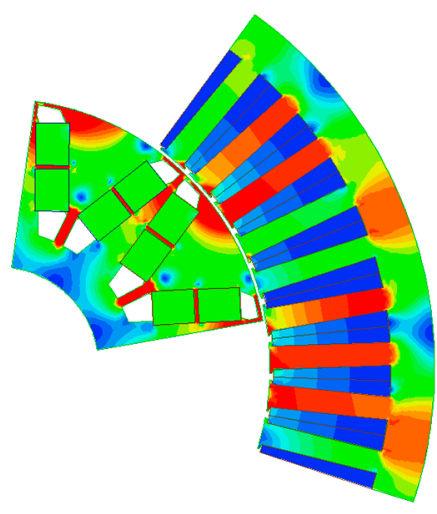

(c) $140 \mathrm{~mm}$

Figure 17. Magnetic flux density of each model.

The inductance and flux linkage of each model when the maximum torque is generated at the rated speed and the maximum speed for which the magnetic saturation is considered are shown in Figure 18. Although the laminate length decreases, as the flux is concentrated, $\lambda_{\mathrm{pm}}$ increases. In the case of the inductance, $\mathrm{L}_{\mathrm{d}}$ does not exhibit a difference, and $\mathrm{L}_{\mathrm{q}}$ decreases as the laminate length decreases. Although the laminate length decreases as the shape of the rotor for the concentration of the flux changes, $L_{d}$ remains almost the same, and $\mathrm{L}_{\mathrm{q}}$ decreases nearly in proportion to the laminate length. Although $\mathrm{L}_{\mathrm{d}}$ exhibits no difference between the rated speed and the maximum speed, $\mathrm{L}_{\mathrm{q}}$ differs by approximately $20 \%$. This is because the maximum-speed section is a linear section where almost no magnetic saturation occurs, owing to the different flux-weakening control from the case of the rated speed. Additionally, the q-axis magnetic path is not affected by the magnetic saturation differently from the d-axis. 


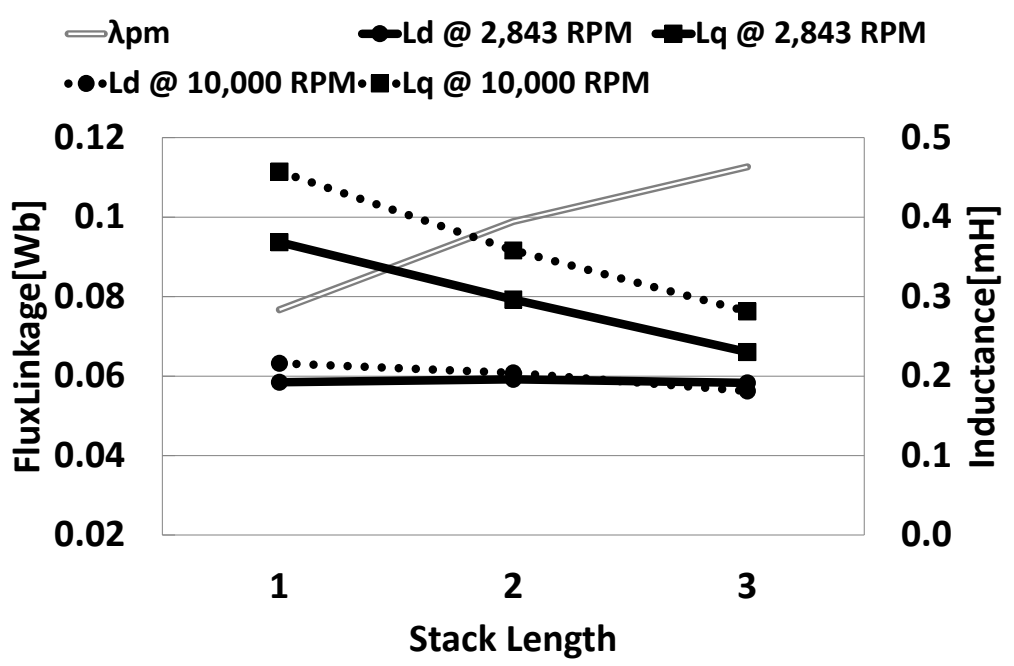

Figure 18. No-load flux linkage and d-q-axis inductance of each model.

The operational characteristics of each model were analyzed by setting the speed to 500 to $10,000 \mathrm{rpm}$, the current to 16 to 550 Apeak, the current phase angle to $80^{\circ}$ or smaller, and the voltage limit to $680 \mathrm{Vdc}$. As indicated by the power-factor map in Figures 19a, 20a and 21a, the more the laminate length decreased, the more the operational range of MTPA increased, and the more the torque generated at the maximum speed increased, expanding the overall operation range. The more the laminate length decreased, the more the power factor increased as a whole, with the exception of high-speed light-load operation. However, as the laminate length decreased to $140 \mathrm{~mm}$, the power factor at the time of high-speed light-load operation rapidly decreased, causing a range where operation is impossible. The range where operation is impossible is the result of analysis performed at a current phase angle of $80^{\circ}$ or smaller. This result may differ for a current phase angle of $80^{\circ}$ or larger. However, in this study, the larger characteristics were analyzed by setting the current phase angle to $80^{\circ}$ or smaller, considering the controllability.

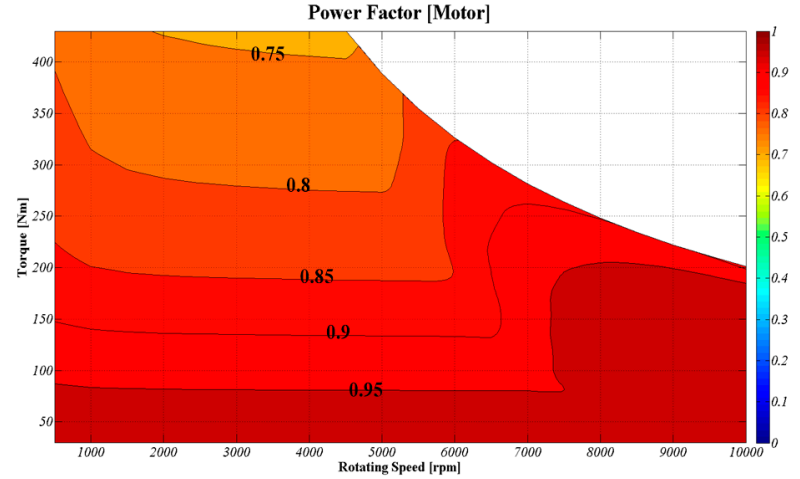

(a) Power-factor

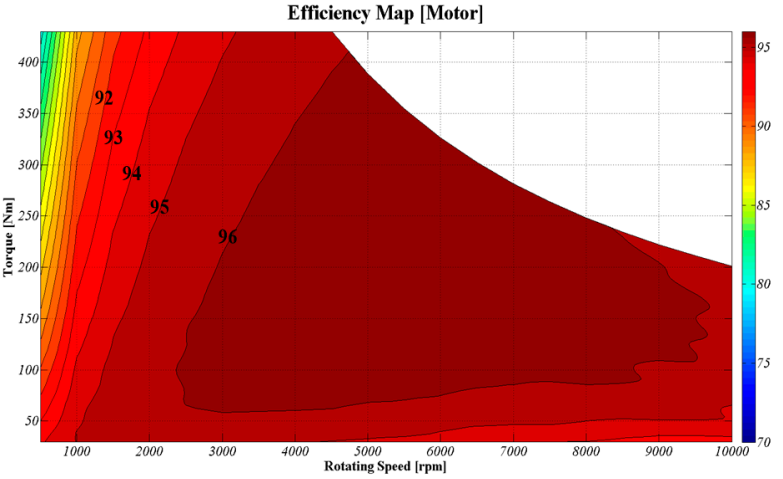

(b) Efficiency map

Figure 19. The $180 \mathrm{~mm}$ model. 


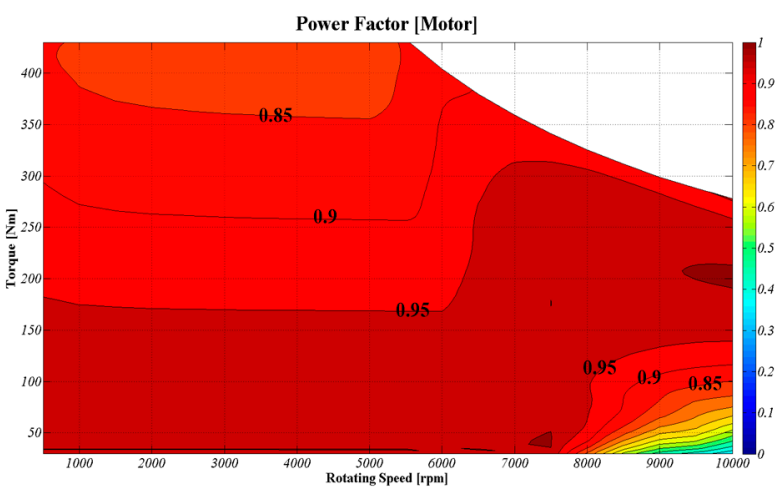

(a) Power-factor

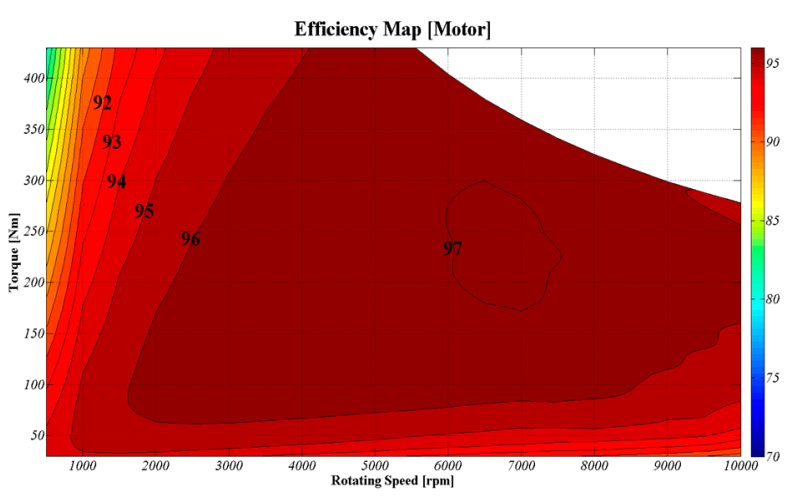

(b) Efficiency map

Figure 20. The $160 \mathrm{~mm}$ model.

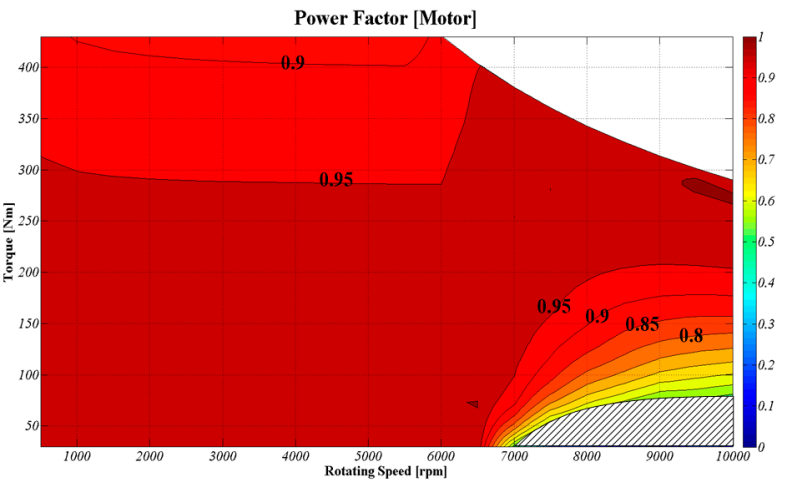

(a) Power-factor

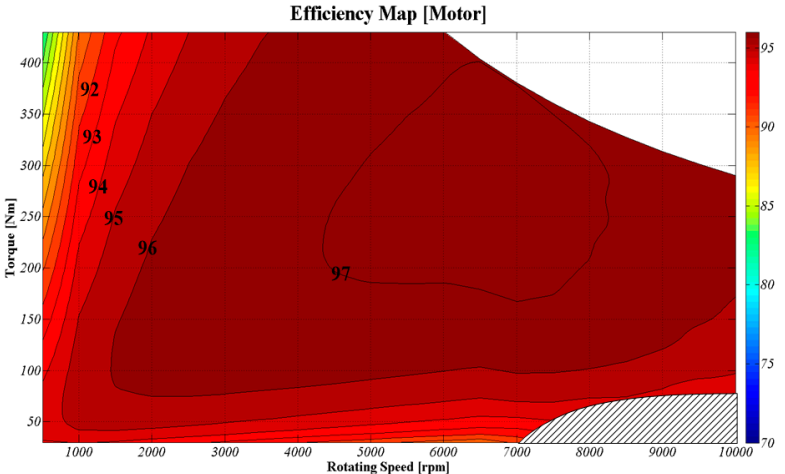

(b) Efficiency map

Figure 21. The $140 \mathrm{~mm}$ model.

Figures $19 b, 20 b$ and $21 b$ shows the efficiency map of each model. As the laminate length decreases, the efficiency increases as a whole. However, as the laminate length decreases, $\lambda_{\mathrm{pm}}$ increases, and the flux-weakening current increases to reduce this, causing not only a reduction in the efficiency during high-speed light-load operation but also a range where operation is impossible in the model with the laminate length of $140 \mathrm{~mm}$.

For a quantitative comparison of the models, Table 5 shows the characteristics of each model predicted by the VP-Map. Table 6 shows the rated-speed and the maximum-speed characteristics of each model at the maximum rating. As the laminate length decreased, the MTPA range increased, the torque generated at the maximum speed increased, and the overall efficiency improved. However, because a range where high-speed light-load operation is impossible occurs and the mechanical safety decreases, a flux-concentrating motor suitable for the target performance should be designed.

Table 5. A comparison of power factor, torque range, and current.

\begin{tabular}{cccccc}
\hline & Specifications & $\mathbf{1 8 0} \mathbf{~ m m}$ & $\mathbf{1 6 0 ~} \mathbf{~ m}$ & $\mathbf{1 4 0} \mathbf{~ m m}$ & Unit \\
\hline \multirow{2}{*}{$2843 \mathbf{~ r p m}$} & Power Factor at 403 Nm & 0.756 & 0.83 & 0.90 & - \\
& Torque range & $10-201$ & $32-278$ & $74-290$ & Nm \\
\multirow{2}{*}{$10,000 \mathrm{rpm}$} & Minimum current for 120 Nm & 225 & 260 & 300 & $\mathrm{~A}$ \\
& Power factor at 120 Nm & 0.999 & 0.896 & 0.733 & - \\
\hline
\end{tabular}


Table 6. A comparison of output characteristics at 2843 and 10,000 RPM.

\begin{tabular}{rccccc}
\hline & & $\mathbf{1 8 0 ~} \mathbf{~ m}$ & $\mathbf{1 6 0} \mathbf{~ m m}$ & $\mathbf{1 4 0 ~} \mathbf{~ m}$ & Unit \\
\hline \multirow{3}{*}{$2843 \mathrm{rpm}$} & Efficiency & 94.4 & 94.8 & 95.2 & $\%$ \\
& PF & 0.756 & 0.830 & 0.900 & - \\
& Line Voltage & 357 & 327 & 293 & $\mathrm{~V}$ \\
\multirow{3}{*}{$10,000 \mathrm{rpm}$} & Efficiency & 95.8 & 95.4 & 95.4 & $\%$ \\
& PF & 0.999 & 0.896 & 0.733 & - \\
& Line Voltage & 679 & 680 & 679 & $\mathrm{~V}$ \\
\hline
\end{tabular}

\section{Final Model and Experimental Results}

The final model, whose shape was designed by considering not only the target performance but also the irreversible demagnetization characteristics of the PM and the mechanical safety of the rotor after designing the size through the determined design parameters, is shown in Figure 22a. The performances of the motors predicted through the VP-MAP and the finite-element analysis are compared in Table 7. The error between the two values is within approximately $7 \%$, which indicates the validity of the motor performance prediction through the VP-Map prior to design.

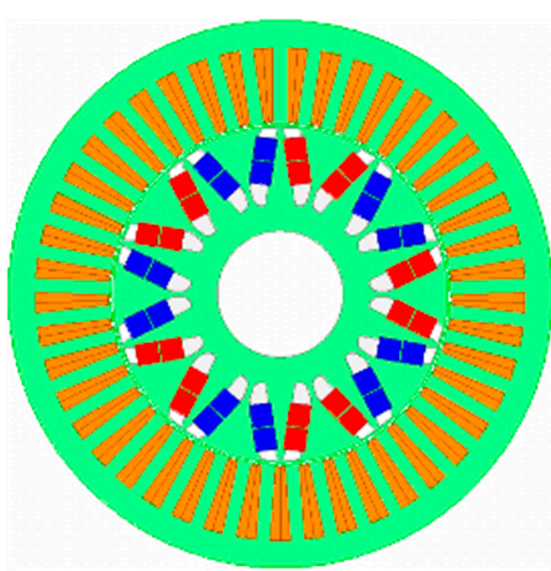

(a) Prototype model

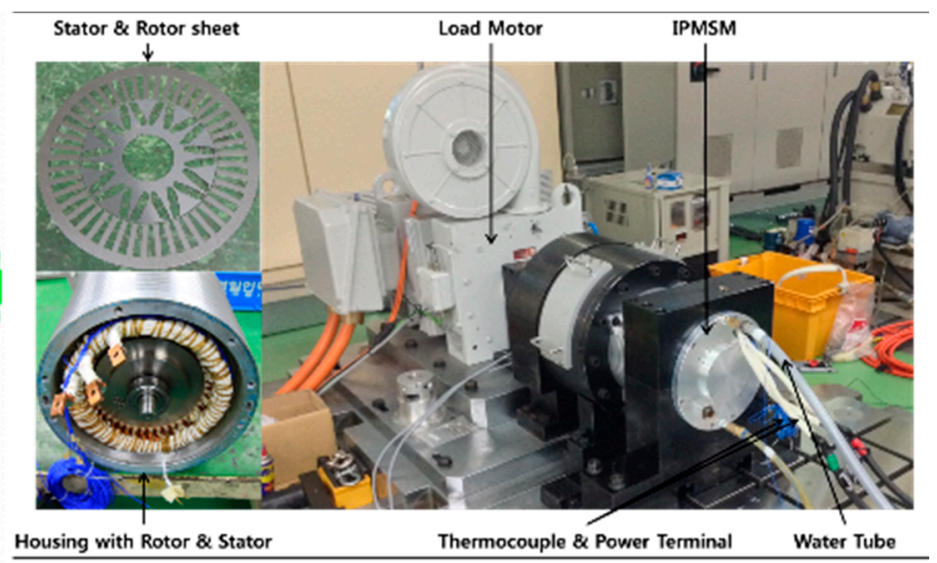

(b) Test Set

Figure 22. The final design model and test dynamometer.

Table 7. Comparison of results between FEA and VP-MAP.

\begin{tabular}{cccccc}
\hline & Specifications & Unit & FEM & VP-Map & Error (\%) \\
\hline \multirow{2}{*}{$2843 \mathrm{rpm}$} & Torque & $\mathrm{Nm}$ & 412.23 & 420 & 1.85 \\
& Maximum torque & $\mathrm{Nm}$ & 247 & 260 & 5.00 \\
$10,000 \mathrm{rpm}$ & Minimum current for 120 Nm & $\mathrm{A}$ & 280 & 275 & 1.82 \\
& Power factor at 120 Nm & - & 0.961 & 0.903 & 6.42 \\
\hline
\end{tabular}

To verify the design validity and the finite-element analysis of the designed motor, a prototype was produced, and a performance test was conducted. Figure $22 \mathrm{~b}$ shows the prototype motor used for the test and a photograph of it mounted on a dynamometer. Motor performance evaluation was performed by applying the developed MCU with a maximum efficiency of about $97.6 \%$.

The torque, efficiency, power factor, and line voltage determined by the speed measured at the momentary rating are shown in Figure 23. The measured values exhibit an accuracy within approximately $4 \%$ compared with the values obtained through finiteelement analysis. Finally, the efficiency maps obtained by a simulation and by a test are shown in Figure 24. Although the efficiency characteristics differ slightly, the difference occurs because it is difficult to accurately consider not only the electromagnetic loss but 
also the mechanical loss. However, the maximum efficiency and the overall trend are similar, confirming the validity of the simulation results.

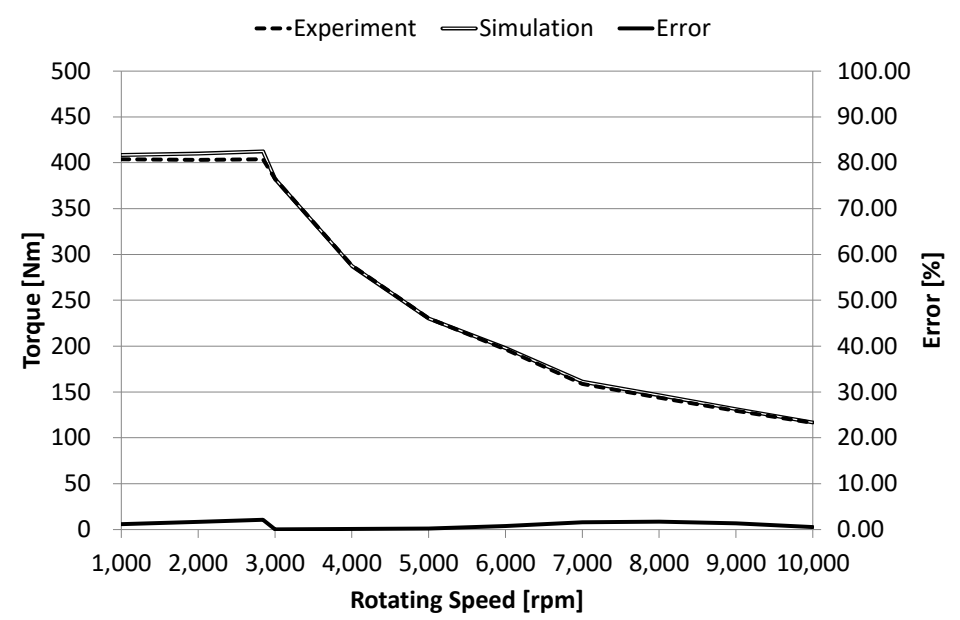

(a) Torque

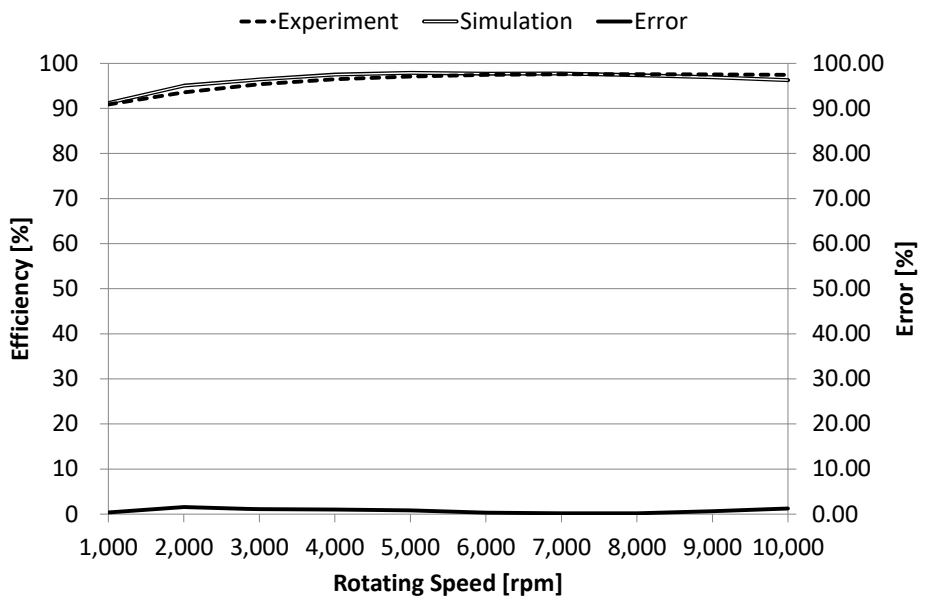

(b) Efficiency

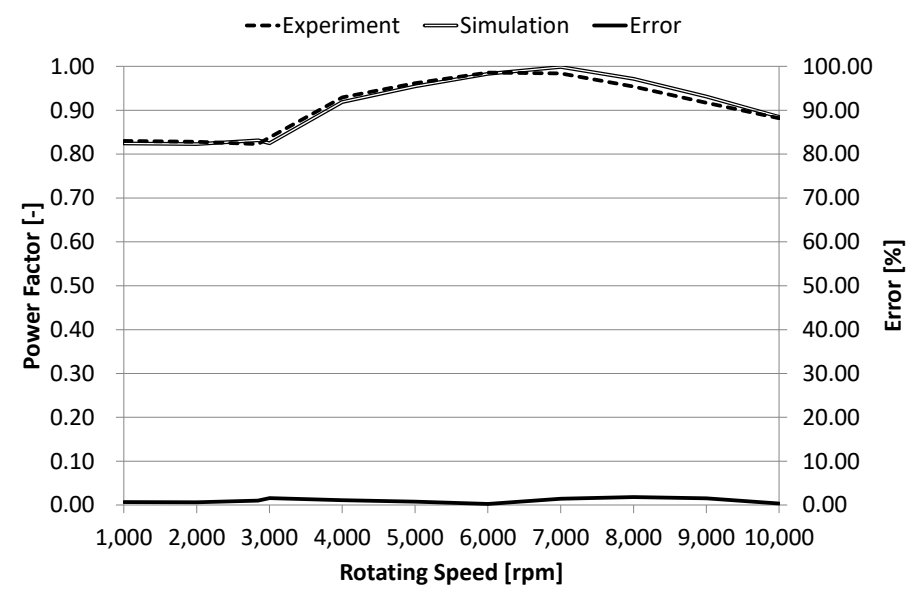

(c) Power factor

Figure 23. A comparison of characteristics between the experiment and simulation at $120 \mathrm{~kW}$. 


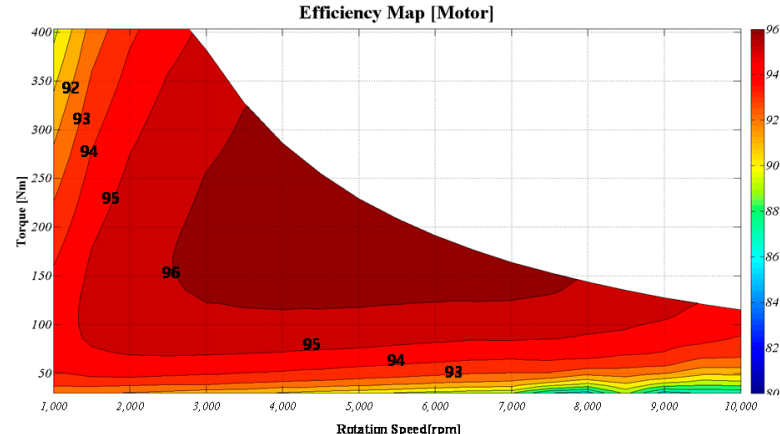

(a) Simulation

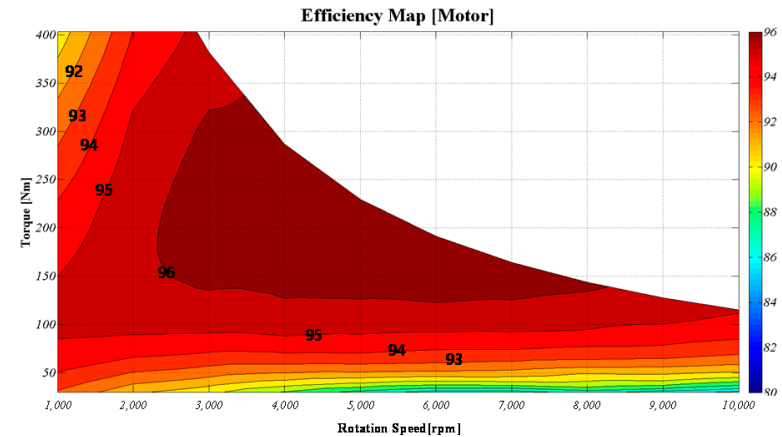

(b) Experiment

Figure 24. Efficiency maps.

\section{Conclusions}

A study was performed on the design of a flux-concentrating PM synchronous motor for HEVs/EVs through a VP-Map-based parameter analysis. The paper is largely divided into a review of the design parameters suitable for a traction motor for HEVs/EVs and the design of an FCPMSM.

It is difficult to predict the output characteristics at the maximum speed, as no constant output characteristics are observed with changes in the parameters at the maximum speed, which differs from the case of the rated speed, particularly because a traction motor for $\mathrm{HEVs} / \mathrm{EV}$ s has a wide operation range and variable load. To resolve this, the VP-Map, which can predict the maximum torque that can be generated at the maximum speed of a PM motor, the current required to generate the rated torque, and whether the operation is possible under a light load, was proposed. Then, the design parameters of the PM motor for HEVs/EVs were determined using the output equation and the VP-Map.

Because the determined parameters cannot be achieved with the shape of a general PM motor, a flux-concentrating PM motor was proposed. A PM motor for HEVs/EVs was designed, and the validity of the proposed method was verified by comparing the results of a finite-element analysis and the VP-Map. Finally, the required performance predicted by the design-parameter analysis was confirmed, and the analysis was validated through a test of the designed motor.

Author Contributions: Conceptualization, K.-D.L. and J.-S.P.; methodology, K.-D.L.; validation, J.-J.L., M.-H.Y. and J.-S.P.; formal analysis, K.-D.L.; investigation, J.-J.L. and M.-H.Y.; data curation, M.-H.Y.; writing—original draft preparation, K.-D.L.; writing—review and editing, K.-D.L.; visualization, K.-D.L.; supervision, J.-S.P. All authors have read and agreed to the published version of the manuscript.

Funding: This work was supported by the Industrial core technology development project (No. 20012518) funded By the Ministry of Trade, Industry, and Energy (MOTIE, Korea).

Institutional Review Board Statement: Not applicable.

Informed Consent Statement: Not applicable.

Data Availability Statement: Not applicable.

Conflicts of Interest: The authors declare no conflict of interest.

\section{References}

1. Chan, C.C. The State of the Art of Electric, Hybrid, and Fuel Cell Vehicles. Proc. IEEE 2007, 95, 704-718. [CrossRef]

2. Kamiya, M. Development of Traction Drive Motors for the Toyota Hybrid System. IEEJ Trans. Ind. Appl. 2006, 126, 473-479. [CrossRef]

3. Yamazaki, K. Loss analysis of permanent magnet motors with concentrated windings-variation of magnet eddy current loss due to stator and rotor shapes. In Proceedings of the 2008 IEEE Industry Applications Society Annual Meeting, Edmonton, AB, Canada, 5-9 October 2008; Volume 45, pp. 1334-1342. 
4. Yamazaki, K.; Kanou, Y. Rotor Loss Analysis of Interior Permanent Magnet Motors Using Combination of 2-D and 3-D Finite Element Method. IEEE Trans. Magn. 2009, 45, 1772-1775. [CrossRef]

5. Cho, H.; Jang, S.; Choi, S. A design approach to reduce rotor losses in high-speed permanent magnet machine for turbo compressor. Magn. IEEE Trans. 2006, 42, 3521-3523. [CrossRef]

6. Seo, J.-H.; Kwak, S.-Y.; Jung, S.-Y.; Lee, C.-G.; Chung, T.-K.; Jung, H.-K. A Research on Iron Loss of IPMSM with a Fractional Number of Slot Per Pole. IEEE Trans. Magn. 2009, 45, 1824-1827. [CrossRef]

7. Bianchi, N.; Bolognani, S.; Pre, M.; Grezzani, G. Design considerations for fractional-slot winding configurations of synchronous machines. IEEE Trans. Ind. Appl. 2006, 42, 997-1006. [CrossRef]

8. Wang, J.; Xia, Z.; Howe, D. Three-phase modular permanent magnet brushless machine for torque boosting on a down-sized ICE vehicle. IEEE Trans. Veh. Technol. 2005, 54, 809-816. [CrossRef]

9. Choi, J.; Chun, Y.; Han, P. Design of high power permanent magnet motor with segment rectangular copper wire and closed slot opening on electric vehicles. IEEE Trans. Magn. 2010, 46, 2070-2073. [CrossRef]

10. Lu, Q.F.; Fan, C.Z.; Ye, Y.Y.; Zhu, Z.Q. A high torque density permanent magnet motor for oil pumping unit. J. Appl. Phys. 2008, 103, 07F108. [CrossRef]

11. Parsa, L.; Hao, L. Interior Permanent Magnet Motors with Reduced Torque Pulsation. IEEE Trans. Ind. Electron. 2008, 55, 602-609. [CrossRef]

12. Kioumarsi, A.; Moallem, M.; Fahimi, B. Mitigation of Torque Ripple in Interior Permanent Magnet Motors by Optimal Shape Design. IEEE Trans. Magn. 2006, 42, 3706-3711. [CrossRef]

13. Zhang, J.; Cheng, M.; Chen, Z. Optimal design of stator interior permanent magnet machine with minimized cogging torque for wind power application. Energy Convers. Manag. 2008, 49, 2100-2105. [CrossRef]

14. Kim, K.-C.; Koo, D.-H.; Lee, J. The Study on the Overhang Coefficient for Permanent Magnet Machine by Experimental Design Method. IEEE Trans. Magn. 2007, 43, 2483-2485. [CrossRef]

15. Fitan, E.; Messine, F.; Nogarede, B. A general analytical model of electrical permanent magnet machine dedicated to optimal design. COMPEL Int. J. Comput. Math. Electr. Electron. Eng. 2003, 22, 1037-1050. [CrossRef]

16. Hamdi, E.S. Design of Small Electrical Machines; Wiley: New York, NY, USA, 1994.

17. Wang, Y.; Xuhui, W.; Xue, S. Analysis and design of high power factor interior permanent magnet motor with concentrated windings for undersea vehicle propulsion. In Proceedings of the 2008 IEEE Vehicle Power and Propulsion Conference, Harbin, China, 3-5 September 2008; pp. 1-6.

18. Wang, X.; Cao, K.; Feng, H.; Guo, L.; Xu, X. Design and Analysis of Permanent Magnet Linear Synchronous Motor with Special Pole Shape. J. Comput. 2013, 8, 478-484. [CrossRef]

19. Ionel, D.M.; Eastham, J.F.; Miller, T.J.E.; Demeter, E. Design considerations for permanent magnet synchronous motors for flux weakening applications. IEE Proc. Electr. Power Appl. 1998, 145, 435-440. [CrossRef]

20. Zhao, F.; Lipo, T.A.; Kwon, B. Dual-stator Interior Permanent Magnet Vernier Machine Having Torque Density and Power Factor Improvement. Electr. Power Compon. Syst. 2014, 42, 1717-1726. [CrossRef]

21. Kataoka, Y.; Takayama, M.; Matsushima, Y.; Anazawa, Y. Investigation of Magnetic Pole Combination in a Surface Permanent Magnet-type Vernier Motor. J. Magn. Soc. Jpn. 2013, 37, 268-272. [CrossRef]

22. Meessen, K.K.; Thelin, P.; Soulard, J.; Lomonova, E. Inductance Calculations of Permanent-Magnet Synchronous Machines Including Flux Change and Self- and Cross-Saturations. IEEE Trans. Magn. 2008, 44, 2324-2331. [CrossRef]

23. Kim, K.-C. A Novel Magnetic Flux Weakening Method of Permanent Magnet Synchronous Motor for Electric Vehicles. IEEE Trans. Magn. 2012, 48, 4042-4045. [CrossRef] 